Cochrane Database of Systematic Reviews

\title{
D-dimer test for excluding the diagnosis of pulmonary embolism
} (Review)

Crawford F, Andras A, Welch K, Sheares K, Keeling D, Chappell FM

Crawford F, Andras A, Welch K, Sheares K, Keeling D, Chappell FM.

$D$-dimer test for excluding the diagnosis of pulmonary embolism.

Cochrane Database of Systematic Reviews 2016, Issue 8. Art. No.: CD010864.

DOI: 10.1002/14651858.CD010864.pub2.

www.cochranelibrary.com 
TABLE OF CONTENTS

HEADER 1

ABSTRACT

PLAIN LANGUAGE SUMMARY

SUMMARY OF FINDINGS

BACKGROUND

Figure 1.

OBJECTIVES

METHODS

Figure 2.

RESULTS

Figure 3.

Figure 4.

DISCUSSION

AUTHORS' CONCLUSIONS

ACKNOWLEDGEMENTS

REFERENCES

CHARACTERISTICS OF STUDIES

ADDITIONAL TABLES

APPENDICES

WHAT'S NEW

N

CONTRIBUTIONS OF AUTHORS

DECLARATIONS OF INTEREST

SOURCES OF SUPPORT

DIFFERENCES BETWEEN PROTOCOL AND REVIEW

INDEX TERMS

1

2

4

7

8

10

10

12

14

14

15

16

17

17

18

22

31

32

41

41

41

41

41

D-dimer test for excluding the diagnosis of pulmonary embolism (Review) 
[Diagnostic Test Accuracy Review]

\section{D-dimer test for excluding the diagnosis of pulmonary embolism}

Fay Crawford ${ }^{1}$, Alina Andras ${ }^{2}$, Karen Welch $^{3}$, Karen Sheares ${ }^{4}$, David Keeling 5 , Francesca M Chappell 6

1NHS Fife, Queen Margaret Hospital, Dunfermline, UK. 2Institute for Science and Technology in Medicine, Keele University, Guy Hilton Research Centre, Stoke-on-Trent, UK. 3Usher Institute of Population Health Sciences and Informatics, University of Edinburgh, Edinburgh, UK. ${ }^{4}$ Papworth Hospital NHS Foundation Trust, Cambridge, UK. 50xford Haemophilia \& Thrombosis Centre, Churchill Hospital, Oxford, UK. ${ }^{6}$ Division of Clinical Neurosciences, University of Edinburgh, Edinburgh, UK

Contact address: Fay Crawford, NHS Fife, Queen Margaret Hospital, Dunfermline, KY12 0SU, UK. fay.crawford@nhs.net.

Editorial group: Cochrane Vascular Group.

Publication status and date: Edited (no change to conclusions), published in Issue 9, 2016.

Citation: Crawford F, Andras A, Welch K, Sheares K, Keeling D, Chappell FM. D-dimer test for excluding the diagnosis of pulmonary embolism. Cochrane Database of Systematic Reviews 2016, Issue 8. Art. No.: CD010864. DOI: 10.1002/14651858.CD010864.pub2.

Copyright (c) 2016 The Cochrane Collaboration. Published by John Wiley \& Sons, Ltd.

\section{A B S T R A C T}

\section{Background}

Pulmonary embolism (PE) can occur when a thrombus (blood clot) travels through the veins and lodges in the arteries of the lungs, producing an obstruction. People who are thought to be at risk include those with cancer, people who have had a recent surgical procedure or have experienced long periods of immobilisation and women who are pregnant. The clinical presentation can vary, but unexplained respiratory symptoms such as difficulty breathing, chest pain and an increased respiratory rate are common.

D-dimers are fragments of protein released into the circulation when a blood clot breaks down as a result of normal body processes or with use of prescribed fibrinolytic medication. The D-dimer test is a laboratory assay currently used to rule out the presence of high D-dimer plasma levels and, by association, venous thromboembolism (VTE). D-dimer tests are rapid, simple and inexpensive and can prevent the high costs associated with expensive diagnostic tests.

\section{Objectives}

To investigate the ability of the D-dimer test to rule out a diagnosis of acute PE in patients treated in hospital outpatient and accident and emergency (A\&E) settings who have had a pre-test probability (PTP) of PE determined according to a clinical prediction rule (CPR), by estimating the accuracy of the test according to estimates of sensitivity and specificity. The review focuses on those patients who are not already established on anticoagulation at the time of study recruitment.

\section{Search methods}

We searched 13 databases from conception until December 2013. We cross-checked the reference lists of relevant studies.

\section{Selection criteria}

Two review authors independently applied exclusion criteria to full papers and resolved disagreements by discussion.

We included cross-sectional studies of D-dimer in which ventilation/perfusion (V/Q) scintigraphy, computerised tomography pulmonary angiography (CTPA), selective pulmonary angiography and magnetic resonance pulmonary angiography (MRPA) were used as the reference standard.

- Participants: Adults who were managed in hospital outpatient and A\&E settings and were suspected of acute PE were eligible for inclusion in the review if they had received a pre-test probability score based on a CPR.

- Index tests: quantitative, semi quantitative and qualitative D-dimer tests. 
- Target condition: acute symptomatic PE.

- Reference standards: We included studies that used pulmonary angiography, V/Q scintigraphy, CTPA and MRPA as reference standard tests.

\section{Data collection and analysis}

Two review authors independently extracted data and assessed quality using Quality Assessment of Diagnostic Accuracy Studies-2 (QUADAS-2). We resolved disagreements by discussion. Review authors extracted patient-level data when available to populate $2 \times 2$ contingency tables (true-positives (TPs), true-negatives (TNs), false-positives (FPs) and false-negatives (FNs)).

\section{Main results}

We included four studies in the review ( $n=1585$ patients). None of the studies were at high risk of bias in any of the QUADAS-2 domains, but some uncertainty surrounded the validity of studies in some domains for which the risk of bias was uncertain. D-dimer assays demonstrated high sensitivity in all four studies, but with high levels of false-positive results, especially among those over the age of 65 years. Estimates of sensitivity ranged from $80 \%$ to $100 \%$, and estimates of specificity from $23 \%$ to $63 \%$.

\section{Authors' conclusions}

A negative D-dimer test is valuable in ruling out PE in patients who present to the A\&E setting with a low PTP. Evidence from one study suggests that this test may have less utility in older populations, but no empirical evidence was available to support an increase in the diagnostic threshold of interpretation of D-dimer results for those over the age of 65 years.

\section{PLAIN LANGUAGE SUMMARY}

\section{D-dimer for excluding pulmonary embolism in hospital outpatient and accident and emergency populations}

\section{Review question}

To investigate the ability of the D-dimer test to rule out a diagnosis of acute pulmonary embolism (PE) in patients treated in hospital outpatient and accident and emergency (A\&E) departments.

\section{Background}

Pulmonary embolism (PE) is a serious, potentially fatal condition that occurs when a blood clot becomes lodged in the blood vessels of the lungs. When people arrive to hospital A\&E departments reporting difficulty breathing, breathlessness and chest pain, several explanations are possible but a quick diagnosis is needed. Tests that are available to detect blood clots in the lungs can be invasive and time-consuming, can carry a radiation burden and may be costly. Quick, easy-to-use and inexpensive tests that can be used to rule out the diagnosis would be very valuable.

One such test is the D-dimer test, which is so named because it detects small pieces of protein in the blood, which are called D-dimer. When someone with symptoms of breathlessness and chest pain arrives to the hospital A\&E department, the staff conducts an examination and asks questions about the patient's medical history and lifestyle. This helps them to calculate a score for the patient's risk that symptoms are due to a PE.

If the score shows that they are at high risk of a blood clot in the lungs, patients undergo diagnostic scanning immediately (or are treated while test results are awaited). A D-dimer test can be ordered for people in low or moderate (or unlikely) risk groups; a negative D-dimer result might rule out the diagnosis of PE without the need for imaging.

\section{Study characteristics}

This review considered all evidence provided by studies that assess the ability of D-dimer to rule out PE in people attending hospital outpatient and A\&E departments.

We assessed all available reports from a wide search of databases of medical literature. Two review authors independently assessed studies that met the review criteria, including use of a study design called a cross-sectional study; inclusion of people with symptoms of PE who attended hospital outpatient and A\&E departments; use of a risk score and then a D-dimer test; and comparison of results of the D-dimer test against the results of the very best available tests - ventilation/perfusion scanning (V/Q scanning), pulmonary angiography, computerised tomography pulmonary angiography, and magnetic resonance pulmonary angiography.

\section{Key results}

Four studies met our criteria, and data from 1585 patients were available. We found evidence that negative (disease absent) D-dimer tests are very good at ruling out $\mathrm{PE}$ and identifying people without $\mathrm{PE}$, but high numbers of false-positive test results suggest that people with 
a raised D-dimer may not in fact have a PE; therefore, a positive result needs to be followed by imaging. In one study, false-positives were more common among people older than 65 years of age.

\section{Quality of the evidence}

The flow of patients and the timing of D-dimer and reference standard tests were of greatest methodological concern; no study authors provided a flow diagram to show the flow of patients throughout their study, and only one study clearly reported the time between administration of index and reference standard tests. In the remaining three studies, timing between conduct of the index test and completion of the reference standard was not clearly reported, leading to an unclear classification of bias.

\section{Conclusions}

Limited evidence from the studies included in this review suggests that quantitative D-dimer tests used in emergency departments have few false-negatives but very high levels of false-positive results, with a high level of sensitivity consistently evident across all age groups. This makes the test useful as a rule-out test but means that a positive result requires diagnostic imaging. 
SUMMARY OF FINDINGS

\section{Summary of findings 1 . Summary of findings table}

D-dimer test for excluding the diagnosis of pulmonary embolism

Population: people suspected of having a pulmonary embolism

Index test: D-dimer test

Target condition: pulmonary embolism

Reference standard: MRPA, pulmonary angiography, V/Q scintigraphy and CTPA

Study design: cross-sectional studies

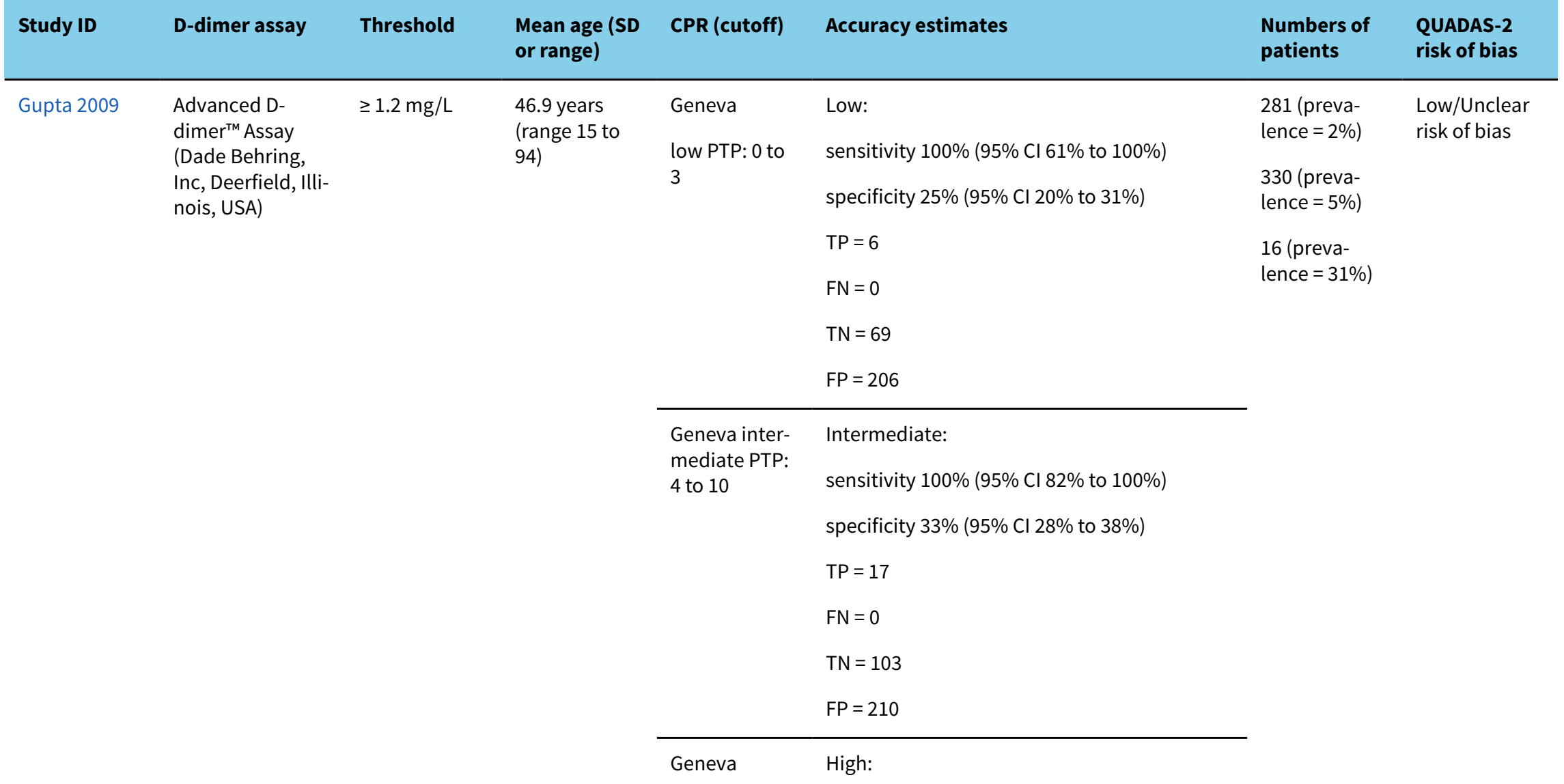




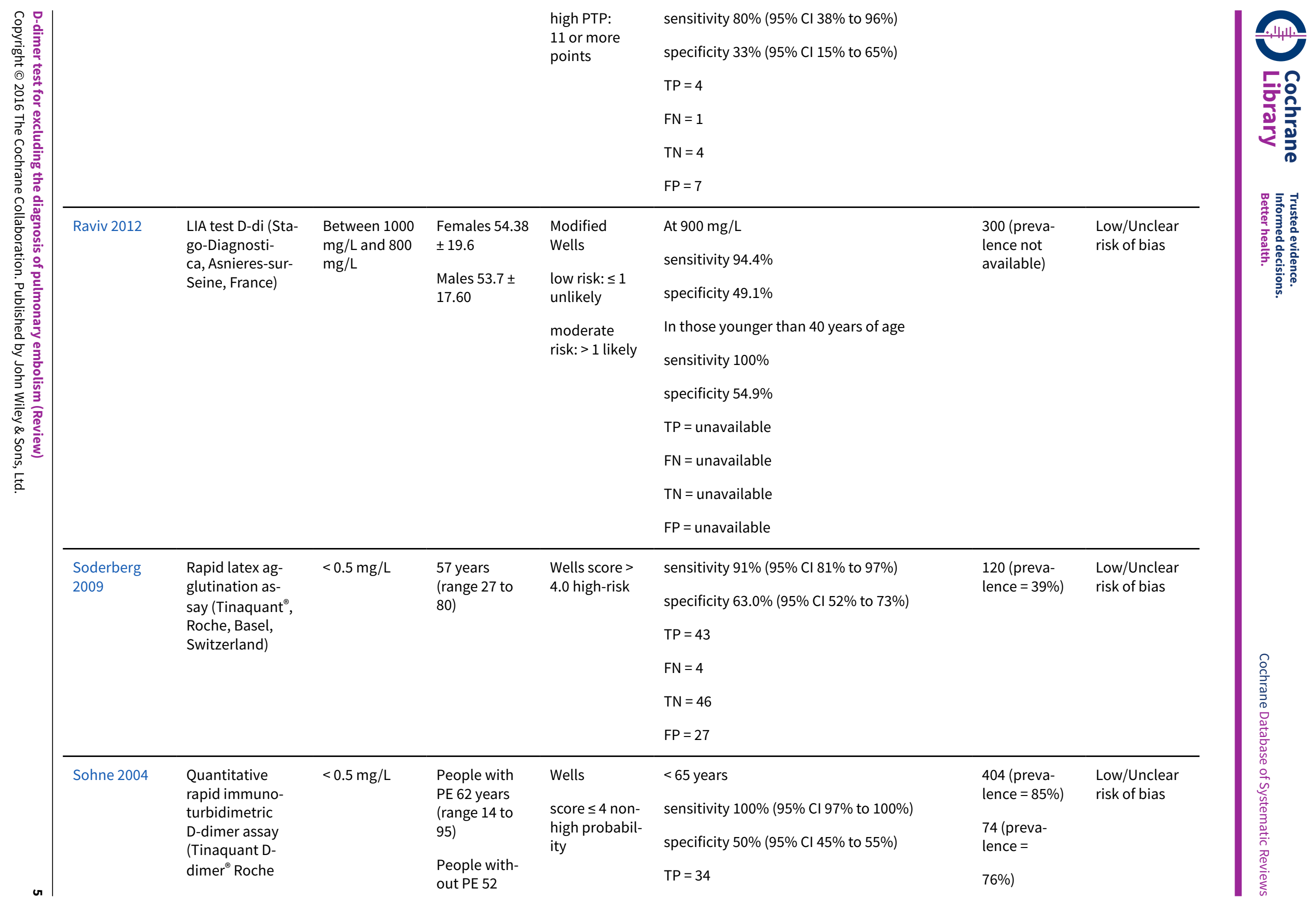


Diagnostica,

Mannheim, Ger-

years (range

many)

17 to 92 )
$\mathrm{FN}=302$

$\mathrm{TN}=34$

$\mathrm{FP}=34$

65 to 75 years

sensitivity $100 \%$ (95\% Cl $85 \%$ to $100 \%)$

specificity $31 \%$ (95\% Cl $20 \%$ to $44 \%)$

$\mathrm{TP}=6$

$\mathrm{FN}=50$

$\mathrm{TN}=6$

$\mathrm{FP}=12$

$>75$ years

sensitivity $100 \%$ (95\% Cl $86 \%$ to $100 \%$ )

specificity $23 \%(95 \% \mathrm{Cl} 12 \%$ to $38 \%)$

$\mathrm{TP}=4$

$\mathrm{FN}=39$

$\mathrm{TN}=4$

$\mathrm{FP}=15$
62 (preva-

lence $=69 \%)$

$\mathrm{Cl}$ : confidence interval

CPR: clinical predication rule

CTPA: computerised tomography pulmonary angiography

$\mathrm{FN}$ : false negatives

FP: false positives

MRPA: magnetic resonance pulmonary angiography

PTP: pre-test probability

QUADAS-2: Quality Assessment of Diagnostic Accuracy Studies-2

SD: standard deviation

TN: true negatives

TP: true positives

V/Q: ventilation/perfusion 


\section{B A C K G R O U N D}

Venous thromboembolism (VTE) is the collective term for deep vein thrombosis (DVT) and pulmonary embolism (PE). PE can occur when a thrombus (blood clot) travels through the veins and lodges in the arteries of the lungs, producing an obstruction. A variety of estimates have been presented for the incidence of PE in different populations; in the USA, the number of first-time PEs ranges from 71 to 117 cases per 100,000 (White 2003).

People thought to be at risk include those with cancer and those who have had a recent surgical procedure, women who are pregnant and individuals who have experienced long periods of immobilisation. The clinical presentation can vary, but unexplained respiratory symptoms such as difficulty breathing, chest pain and an increased respiratory rate are commonly observed (Ainish 1999). As these features can be present in a number of other conditions, including myocardial infarction, pneumonia and heart failure (Goldhaber 1998), the diagnosis of PE can be difficult to rule out on the basis of clinical presentation alone, and it is estimated that only $25 \%$ of patients who present with symptoms and signs of PE actually have the condition (van Belle 2006). Failure to diagnose accurately and treat a PE can be fatal, and immediate treatment with an anticoagulant to prevent development of further clots is critically important (Andras 2012). Several radiological and laboratory tests are used to diagnose PE; these tests exhibit different accuracies, have different costs and, because some are invasive and others non-invasive, are associated with different levels of risk (Goodacre 2006; Yoo 2012).
D-dimers are fragments of protein released into the circulation when a blood clot breaks down as a result of normal body processes or with use of prescribed fibrinolytic medication. The normal level of plasma D-dimer is usually less than $\mathbf{5 0 0}$ micrograms per litre $(\mu \mathrm{g} / \mathrm{L})$ (upper limit of normal can vary depending on method of measurement), and a higher level of D-dimer may be due to the presence of a DVT or PE. D-dimers can be measured by an enzymelinked immunosorbent assay (ELISA) or by use of coated latex particles that agglutinate in the presence of plasma containing Ddimer, with the degree of agglutination directly proportionate to the concentration of D-dimer in the plasma (Than 2009). However, plasma D-dimer levels can be influenced by a person's age, by whether he or she has cancer or has had recent surgery or by pregnancy, leading to false-positive test results. As D-dimer antigen levels are raised in the acute phase of PE for around seven days, patients with a PE who present late may have low levels of D-dimer (Schreiber 2002).

Use of D-dimer in the diagnostic pathway is usually preceded by calculation of a pre-test probability with a clinical prediction rule (CPR) such as the Charlotte or Wells score (see Figure 1 and Clinical pathway section below). Patients who are judged likely to have PE (have a high pre-test probability) do not usually receive a D-dimer test; instead, they undergo computerised tomography pulmonary angiography (CTPA) or ventilation/perfusion scintigraphy (V/Q scan). Patients judged to have a low pre-test probability are given a D-dimer test. If the result of the D-dimer is positive, patients will then have a CTPA or V/Q scan. Those with a negative D-dimer test result following a low probability CPR score are considered to not have a PE (NCGC 2012). 
Figure 1. Clinical pathway.

\section{Wells score}

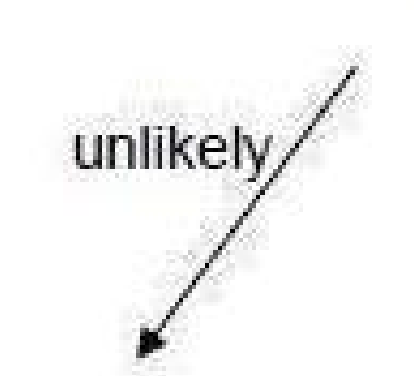

\section{D-dimer}

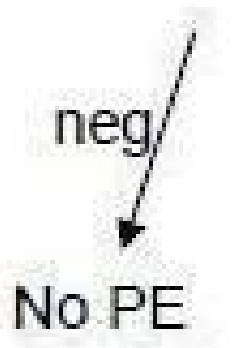

\section{likely}
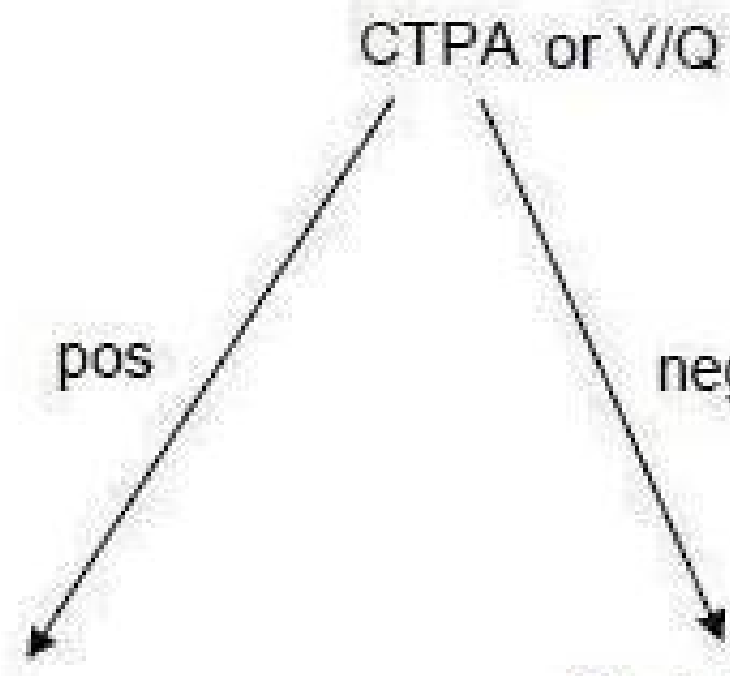

$\mathrm{PE}$

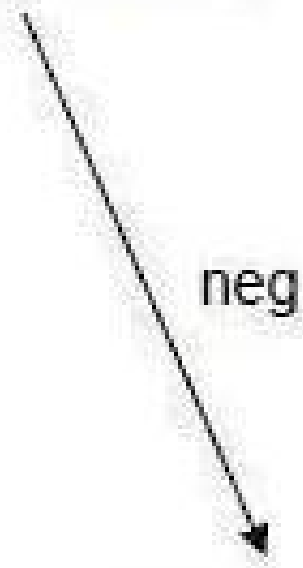

No PE

A previous systematic review included patients recruited with VTE (that is, both DVT and PE) from both inpatient and outpatient settings (Di Nisio 2007). Our Cochrane review will focus on patients with PE in the outpatient setting alone. Most inpatients who experience symptoms or signs suggestive of PE are likely to have a raised $\mathrm{D}$-dimer for other reasons, making the test of little use (Schrecengost 2003).

Tests used to reach a definitive diagnosis of $P E$ include selective pulmonary angiography, CTPA, V/Q scanning and magnetic 
resonance pulmonary angiography (MRPA). Selective pulmonary angiography is an invasive procedure involving insertion into the vascular system, via the arm, groin or neck, of a catheter, which is then guided until it reaches the pulmonary artery. Once the catheter is in place, a contrast agent is injected into the catheter and a series of $x$-rays are taken, allowing the contrast agent to indicate blockages in the arteries. Aside from possible injury from the catheter or contrast reaction, patients receive a dose of radiation. During V/Q scanning, patients have to inhale a gaseous radionuclide and receive an injection of a radioactive agent. By detecting radiation, a scintillation camera then captures images that show circulation of both air and blood in the lungs. CTPA is less invasive than pulmonary angiography but requires the use of a potentially nephrotoxic contrast agent and $x$-rays. MRPA does not use $x$-rays but instead models the response of hydrogen atoms within the body to very strong magnetic fields to produce images. MRPA is therefore unsuitable for patients fitted with pacemakers or other metallic devices, and for those who suffer from claustrophobia, owing to the fact that patients have to lie in a narrow space for the MRPA scan to take place. Although it has been found to be accurate for the diagnosis of proximal PE, MRPA exhibits limited sensitivity for distal (small vessel) disease (Revel 2012) and requires injection of a potentially nephrotoxic contrast agent. Both CTPA and MRPA are considered less invasive and therefore are generally used in preference to selective pulmonary angiography. V/Q scanning is of limited value for those with other cardiorespiratory conditions and is helpful in those with renal failure. However, all of these tests have drawbacks, including their invasive nature, use of chemicals, radiation burden and comparative lack of accessibility, for example, computed tomography (CT) or magnetic resonance (MR) scanner time is not always readily available for comparison with the $\mathrm{D}$-dimer test. Advantages of these tests over D-dimer include that they are more accurate and so can be used to diagnose PE, while D-dimer can be used only to exclude PE. We will use these tests as reference standards.

\section{Target condition being diagnosed}

Acute pulmonary embolism.

\section{Index test(s)}

The D-dimer test is a laboratory assay currently used to rule out the presence of high D-dimer plasma levels and, by association, $\mathrm{PE}$. It is used as an add-on test in practice, and a normal D-dimer on its own is sufficient to rule out PE in patients with a low or moderate/unlikely score or unlikely pre-test probability from a CPR. These tests use routine blood samples and are rapid, simple and inexpensive. D-dimer tests are classified in three different ways according to the manner in which test results are obtained (with final detection using fluorescence, immunosorbent assay or agglutination techniques): quantitative, semi quantitative or qualitative (Goodacre 2006).

Quantitative D-dimer tests measure the plasma concentration of D-dimer. Examples of these D-dimer tests include enzyme-linked immunofluorescent immunoassays (ELFAs), microplate enzymelinked immunosorbent assays (ELISAs) and latex quantitative and latex semi quantitative tests. Qualitative D-dimer tests are also available. Some D-dimer tests are available for point of care (POC) use. They have a rapid turn-around time and are inexpensive. Lack of standardisation of D-dimer assays means that results from one assay cannot be generalised to other assays.

A systematic review by Becker 1996 found that a variety of thresholds have been used in primary studies even for the same tests. Therefore, we intend to include all evaluations of the diagnostic test accuracy of D-dimer regardless of the threshold used to define a positive test result.

\section{Pre-test probability score using clinical prediction rules (CPRs)}

Assessment of the pre-test probability (PTP) of a PE is considered a standard component of current clinical practice; therefore, we included only studies that assess the PTP of PE using a CPR. Many CPRs are available for assessing the PTP of PE; a systematic review identified those that have been most extensively subjected to validation (Ceriani 2010; Wells 1997). We included studies that assess the PTP of PE using any of the following CPRs as part of the diagnostic strategy involving any D-dimer test: Geneva (including Revised and Revised Simplified), Wells (two-level, three-level and simplified) and the Charlotte rule. Table 1 shows commonly used CPRs and their scoring systems for assessment of the PTP of PE. We did not use the Miniati rule, which was assessed in a systematic review (Ceriani 2010), because it does not provide an easy method of scoring patients: Users of the Miniati rule have to calculate a probability from the co-efficients of a logistic regression model, making it less likely to be used than CPRs with easy scoring systems (Laupacis 1997).

\section{See Table 1.}

\section{Clinical pathway}

As explained above, symptomatic patients generally undergo PTP testing by the PE Wells test before they are given any D-dimer test (Ceriani 2010; NCGC 2012; Wells 2006). The two-level Wells test is a CPR that provides patient points for each criterion met (e.g. previous history of PE or DVT, clinical signs of PE, recent surgery or immobilisation, heart rate $>100$ beats per minute (bpm)). The maximum score is 12.5 points; the clinical probability of $P E$ is considered unlikely if the score is 4 or less, and high if the score is higher than 4. The three-level Wells test uses the same scoring system, with scores from 0 to 1 indicating low risk, 2 to 6 intermediate risk and higher than 6 high risk (Wells 2007).

Symptomatic patients considered to be at low risk by the CPR will generally undergo D-dimer testing. A normal D-dimer in patients with a low or unlikely PTP can be used to rule out PE. In these circumstances, doctors will look for non-PE causes of the symptoms. Patients with a low risk score but a positive D-dimer test are referred for CTPA or V/Q scanning. Patients with a high risk score usually do not receive a D-dimer test but are directly referred for CTPA or V/Q scanning. Furthermore, patients may be offered anticoagulation treatment before the CTPA scan if rapid access is not available and they are classed as high risk by the CPR or have a positive $\mathrm{D}$-dimer test result.

\section{Rationale}

Pulmonary embolism is difficult to rule out on the basis of clinical features. Although unnecessary treatment of patients with anticoagulants carries risk, the mortality rate for people with $\mathrm{PE}$ in whom the condition is not recognised and consequently remains untreated is $22 \%$ (Wells 2007). A quick, accurate diagnostic test 
that can rule out the condition and reduce the need for diagnostic imaging represents a clear improvement for treatment of people with this acute condition.

\section{OB JECTIVES}

To investigate the ability of the D-dimer test to rule out a diagnosis of acute PE in patients treated in hospital outpatient and accident and emergency (A\&E) settings who have had a pre-test probability (PTP) of PE determined according to a clinical prediction rule (CPR), by estimating the accuracy of the test according to estimates of sensitivity and specificity. The review focuses on those patients who are not already established on anticoagulation at the time of study recruitment.

\section{Secondary objectives}

To investigate the following as potential sources of heterogeneity: age, sex, previous $\mathrm{PE}$, prolonged immobilisation and type of reference standard. We recognise that all of these listed items except type of reference standard are patient-specific rather than study-specific, and we anticipate that study reports may lack the necessary level of detail to enable an informative analysis.

\section{METHODS}

\section{Criteria for considering studies for this review}

\section{Types of studies}

We included cross-sectional studies evaluating the diagnostic test accuracy of D-dimer and diagnostic cohort studies, including both prospective and retrospective designs. We excluded diagnostic case-control studies (two-gate design). Case-control designs are known to overestimate the sensitivity and specificity of a diagnostic test in clinical practice (Rutjes 2005). In this review, we considered studies that use a CPR with D-dimer testing to rule out PE in patients treated in outpatient and A\&E departments. Specifically, we included studies that recruited symptomatic outpatients with low-, intermediate- or high-risk CPR scores.

\section{Participants}

Adults treated in hospital outpatient and A\&E settings and suspected of acute PE as a result of clinical features such as breathlessness, chest pain, coughing up blood, increased respiratory rate, tachycardia, low blood pressure and fainting, in whom a PTP of PE has been assessed by a CPR for PE (examples of which can be found above under the heading Index test(s)) were eligible for inclusion in the review. When the data were available, we intended to group patients according to whether or not they received anticoagulant treatment, the specific CPR and the D-dimer assay, as these are not standardised (Schreiber 2002).

Patients with indeterminate or conflicting test results may undergo repeat imaging; the most commonly used imaging test for this is CTPA or V/Q scanning, but eligibility criteria of the review specify inclusion only of studies investigating the diagnostic accuracy of the initial D-dimer test. We excluded studies that included pregnant women, people with cancer and mixed groups of patients, when results were not reported separately for those who are pregnant or with and without cancer.

\section{Index tests}

Quantitative, semi quantitative and qualitative D-dimer tests.

\section{Target conditions}

Acute pulmonary embolism (PE).

\section{Reference standards}

We included studies that used various reference standards (RS) encompassing pulmonary angiography, V/Q scintigraphy, CTPA and MRPA. We judged all patients' D-dimer tests (index tests) against these reference tests.

\section{Search methods for identification of studies}

We applied no restrictions in terms of date, language of publication or publication status, and we used no diagnostic methodology search filters.

\section{Electronic searches}

We searched the following databases (date of last search 12 December 2013).

- MEDLINE (Ovid SP).

- EMBASE (Ovid SP).

- Cumulative Index to Nursing and Allied Health Literature (CINAHL) (via EBSCO).

- Latin American and Caribbean Health Science Information Database (LILACS) (Bireme).

- Database of Abstracts of Reviews of Effects (DARE) and the Health Technology Assessment Database (HTA) in The Cochrane Library.

- Institute for Scientific Information (ISI) Conference Proceedings Citation Index - Science.

- British Library Zetoc conference search (http:// zetoc. mimas.ac.uk/wzgw?f=f\&form=conference\&id=31759069).

- MEDION (www.mediondatabase.nl/), via the 'Systematic Reviews of Diagnostic Studies' search filter.

We used the search strategies shown in Appendix 1; Appendix 2; Appendix 3; Appendix 4; Appendix 5; Appendix 6; Appendix 7 and Appendix 8.

We searched the following trial databases for details of ongoing and unpublished studies.

- World Health Organization International Clinical Trials Registry Platform (http://apps.who.int/trialsearch/).

- ClinicalTrials.gov (http://clinicaltrials.gov/).

- Current Controlled Trials (http://www.controlled-trials.com/).

We used the search strategies shown in Appendix 9; Appendix 10 and Appendix 11.

\section{Searching other resources}

We checked the reference lists of primary studies and reviews identified through electronic searches. 


\section{Data collection and analysis}

\section{Selection of studies}

One review author (FC) screened titles and abstracts retrieved by electronic searches, and a second review author (AA) checked a random sample of $10 \%(n=500)$ of identified titles and abstracts. Disagreement was less than $80 \%$, and we resolved disagreements by discussion. One review author (FC) obtained and screened
782 full-text reports, identifying 54 full-text papers for potential eligibility. Two review authors (FC and $\mathrm{AA}$ ) independently applied the inclusion criteria to all 54 full-text reports and disagreed about the inclusion of five (9\%) studies; after discussion, we excluded all five studies. We present a PRISMA (Preferred Reporting Items for Systematic Reviews and Meta-Analyses) flow diagram in Figure 2 to show the decision-making process for including studies in the review (PRISMA 2009). 
Figure 2. Study flow diagram (see table of Excluded studies for reasons for full-text exclusions).

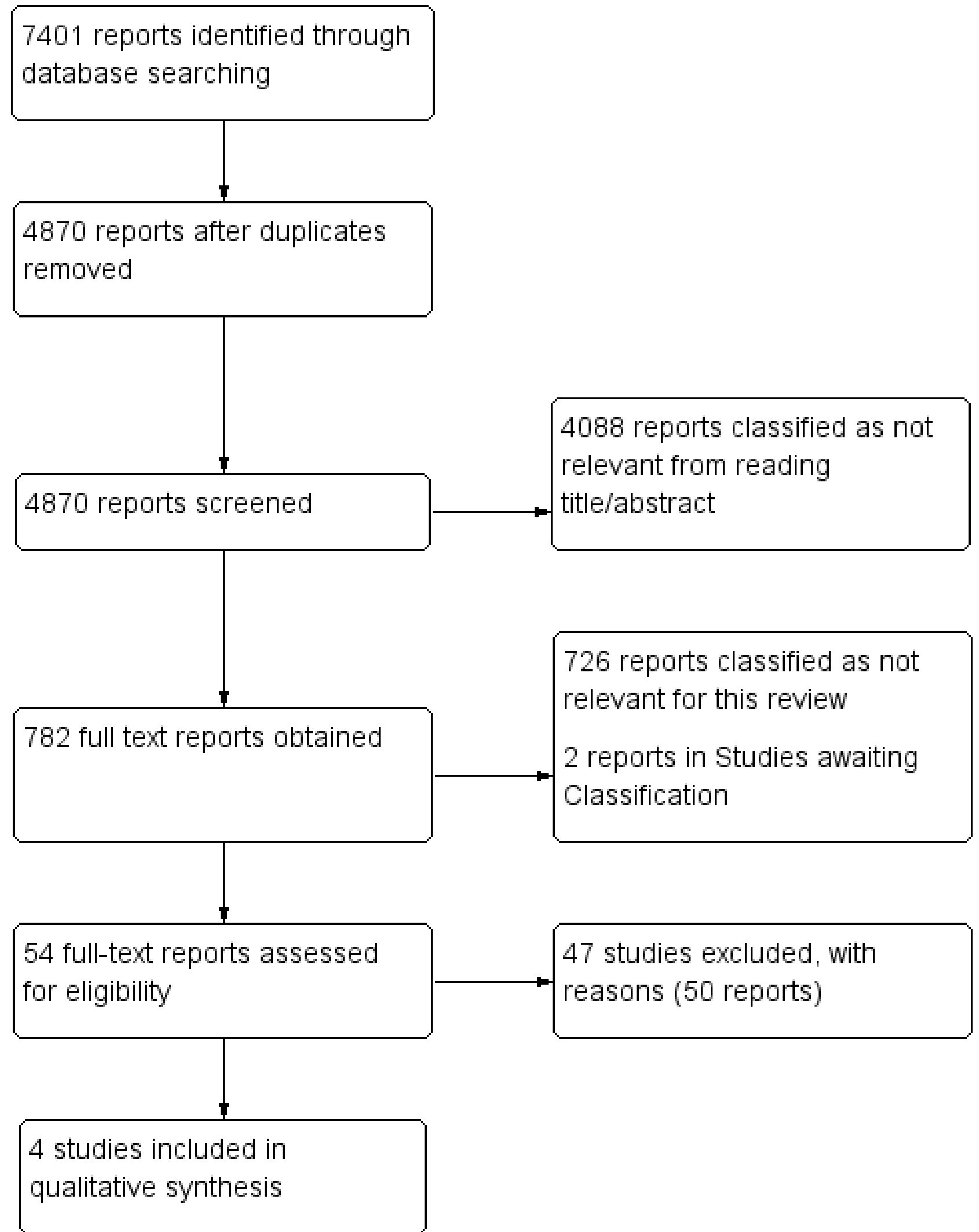


according to one of the specified CPRs and the reference standard used was pulmonary angiography, CTPA, V/Q scanning or MRPA. We reported in the PRISMA flow diagram the number of studies failing these criteria.

\section{Data extraction and management}

Two review authors (FC and $A A$ ) independently replicated data extraction using a standard form. Data collected included details about study design, characteristics of the patient population (age, sex, elements of patient history such as prolonged immobilisation, cancer, recent surgical procedures or previous PE), D-dimer tests given (nature of the D-dimer test such as ELISA, latex agglutination assay, whole blood agglutination), CPRs and all reference standard tests used and data regarding the threshold applied for each test. We also extracted the methods used to conduct each test along with $2 \times 2$ accuracy data.

The $2 \times 2$ accuracy data comprise cross-tabulated results of D-dimer tests and reference standards reported in $2 \times 2$ contingency tables. We extracted patient-level data to populate $2 \times 2$ contingency tables (true-positives (TPs), true-negatives (TNs), false-positives (FPs) and false-negatives (FNs)) as reported, or we back-calculated data from estimates of sensitivity, specificity, positive predictive value, negative predictive value and number of patients. We extracted accuracy data and compared them for patient subgroups classified by PTP as low, intermediate and high.

The data extraction form incorporated a quality assessment section comprising items from Quality Assessment of Diagnostic Accuracy Studies-2 (QUADAS-2) (Whiting 2011). We collected data on mortality, adverse events and numbers of technical failures for both D-dimer and reference standard tests, when available, together with information on the anticoagulant status of patients. Review authors corroborated their extracted data and resolved differences in quality assessment by discussion.

\section{Assessment of methodological quality}

We used the QUADAS-2 (Whiting 2011) to incorporate the review question, a flow diagram when necessary and an assessment of risk of bias and applicability judgements. Review-specific signalling questions and appropriate items concerning the applicability of primary studies relative to the review, together with guidance about ratings, can be found in Appendix 12. Two review authors working independently piloted the data extraction and quality assessment tools before use.

\section{Statistical analysis and data synthesis}

We extracted $2 \times 2$ contingency tables to estimate sensitivity and specificity for each study. We intended that these estimates would be used to create receiver operating characteristic (ROC) plots and forest plots for all studies.

Quantitative D-dimer tests are used with explicit thresholds, and $500 \mu \mathrm{g} / \mathrm{L}$ is a common choice (Schouten 2013). If we had found sufficient studies using this threshold, we would have performed a bivariate random-effects model meta-analysis of sensitivity and specificity to produce clinically applicable summary estimates of sensitivity and specificity. However, we found only four studies in total, and this method of meta-analysis was not possible with only four studies. The bivariate (and equivalent hierarchical summary receiver operating characteristic (HSROC)) model for meta-analysis of diagnostic studies requires estimation of five parameters. It is a relatively complex meta-analysis model in comparison with those used for randomised controlled trials (RCTs) owing to the two-dimensional nature of the data (sensitivity and specificity). Complex models need additional data to ensure adequate estimation of all parameters.

We expected to include studies using qualitative D-dimer tests with no explicit threshold, and so we would have considered fitting the HSROC model to the data and presenting results as summary ROC (SROC) curves to give an indication of the global performance of qualitative D-dimer tests (Harbord 2007), but again the number of studies was insufficient for this analysis. In our protocol, we specified that we would need a minimum of six studies to assess the suitability of studies for meta-analysis.

If the model fit of the bivariate or HSROC model were not acceptable, we considered performing univariate meta-analyses for sensitivity and specificity. However, methodological differences between studies (e.g. type of D-dimer used) would have made the results of any such meta-analysis dubious.

\section{Investigations of heterogeneity}

In our investigations of heterogeneity, we intended to specifically investigate types of reference standards and age, sex and aspects of patient history (prolonged immobilisation or previous $\mathrm{PE}$ ) by including these as co-variates in the meta-analysis (Di Nisio 2007).

We planned that each meta-regression would be carried out separately for each index test and each patient group by adding the items as co-variates to the bivariate model. When data for our prespecified variables were insufficient, we intended to consider analysing one or two other items when data were available and were considered to be clinically relevant, and we intended to clearly label these as post hoc in the review.

We intended that we would examine other potential sources graphically for signs that they are a cause of heterogeneity (Smidt 2008). We would group estimates according to all items listed as potential sources of heterogeneity and presented in forest and ROC plots for visual assessment of heterogeneity.

However, we were unable to carry out any of our planned analyses owing to an insufficient number of studies.

\section{Sensitivity analyses}

We planned to perform separate meta-analyses on groups of studies by which groups would be assigned according to CPR, anticoagulant treatment and specific D-dimer assay. The disease spectrum of patients could vary with CPR and thus affect the estimates of sensitivity and specificity. We were aware that anticoagulant treatment could cause disease progression bias if administered between D-dimer testing and use of the reference standard. D-dimer assays are not standardised and so may have different accuracies. Again, given the small number of studies, we did not attempt to perform any sensitivity analyses.

\section{Assessment of reporting bias}

Methods for dealing with publication bias in reviews of diagnostic accuracy studies are relatively underdeveloped. Consequently, we interpreted our results cautiously and with awareness of the likelihood of publication bias. Had we undertaken a meta-analysis 
of data, we would have considered using a funnel plot of the log of the diagnostic odds ratio (InDOR) (Deeks 2005) when heterogeneity was low in the InDOR.

\section{RES U LTS}

\section{Results of the search}

See the study flow diagram (Figure 2).

We obtained and scrutinised a total of 54 full-text reports to assess their eligibility for inclusion in the review. Forty-seven studies (50 reports) did not meet the eligibility criteria, and we excluded them (Barsotti 1987; Bounameaux 1988; Bounameaux 1991; Bounameaux 1992; Christopher Study; Courtney 2008; deBastos 2008; Demers 1992; de Moerloose 1996; Djurabi 2009; Douma 2011; Eilas 2005; Faivre 1990; Friera-Reyes 2005; Gavaud 1996; Geersing 2012; Ghanima 2005; Ghanima 2007; Goekoop 2007; Harper 2007; Hirai 2007; Hochuli 2007; Hogg 2005; Kabrhel 2007; Kline 1997; Kline 2002; Kline 2006; Kovacs 2001; Laaban 1997; LeGal 2006; Legani 2009; Lucassen 2010; Lucassen 2013; Parent 2007; Park 2008; Perrier 1996; Perrier 1997; Ray 2006; Reber 2007; Righini 2004; Scarvelis 2008; Sebestyen 1990; Soo Hoo 2011; Soons 2000; Than 2009; Waser 2005; Yamaki 2007).
We have provided details of the reasons for exclusion of each of these studies in the Characteristics of excluded studies table. In brief, a common reason for exclusion was the fact that studies did not include all patients who had a D-dimer test in the analysis (e.g. all patients with a positive test result) (Courtney 2008; deBastos 2008; Djurabi 2009; Friera-Reyes 2005; Ghanima 2005; Ghanima 2007; Goekoop 2007; Kovacs 2001; Righini 2004). Another common reason for exclusion was the omission of a CPR in the diagnostic pathway to assess the pre-test probability of study patients (Bounameaux 1988; Bounameaux 1991; de Moerloose 1996; Demers 1992; Faivre 1990; Gavaud 1996; Harper 2007; Kline 1997; Laaban 1997; LeGal 2006; Perrier 1996; Perrier 1997; Ray 2006; Sebestyen 1990; Soons 2000). We were unable to obtain copies of two reports (Ahamad 2000; Undurrage 2001) for which citations are listed in the Studies awaiting classification section. We have included four studies in the review (Gupta 2009; Raviv 2012; Soderberg 2009; Sohne 2004).

\section{Methodological quality of included studies}

See Figure 3 and Figure 4.

Figure 3. Risk of bias and applicability concerns graph: review authors' judgements about each domain presented as percentages across included studies.

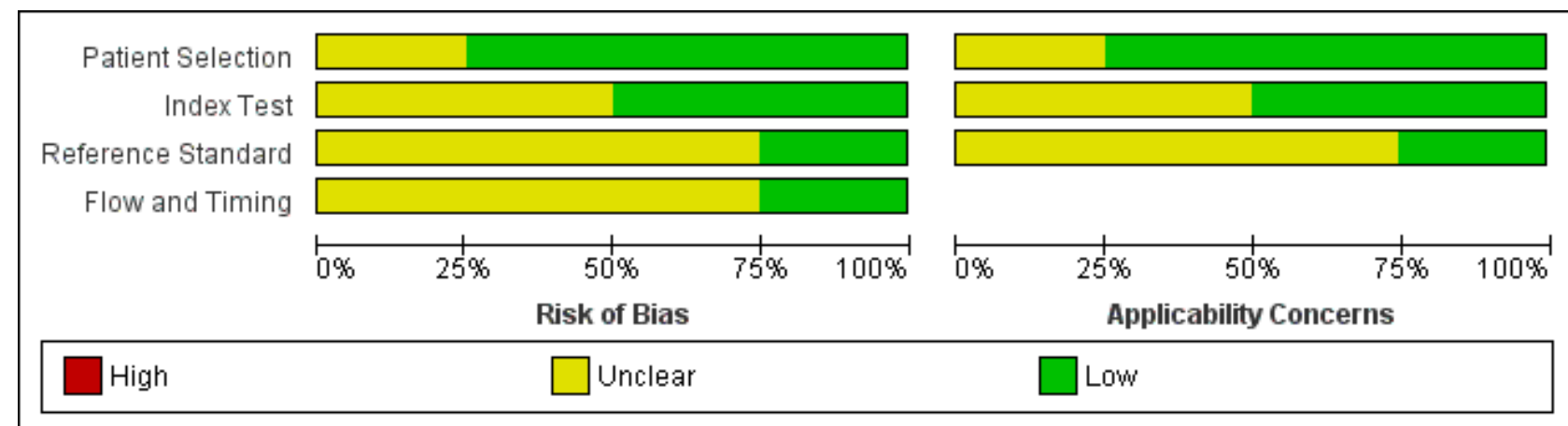


Figure 4. Risk of bias and applicability concerns summary: review authors' judgements about each domain for each included study.

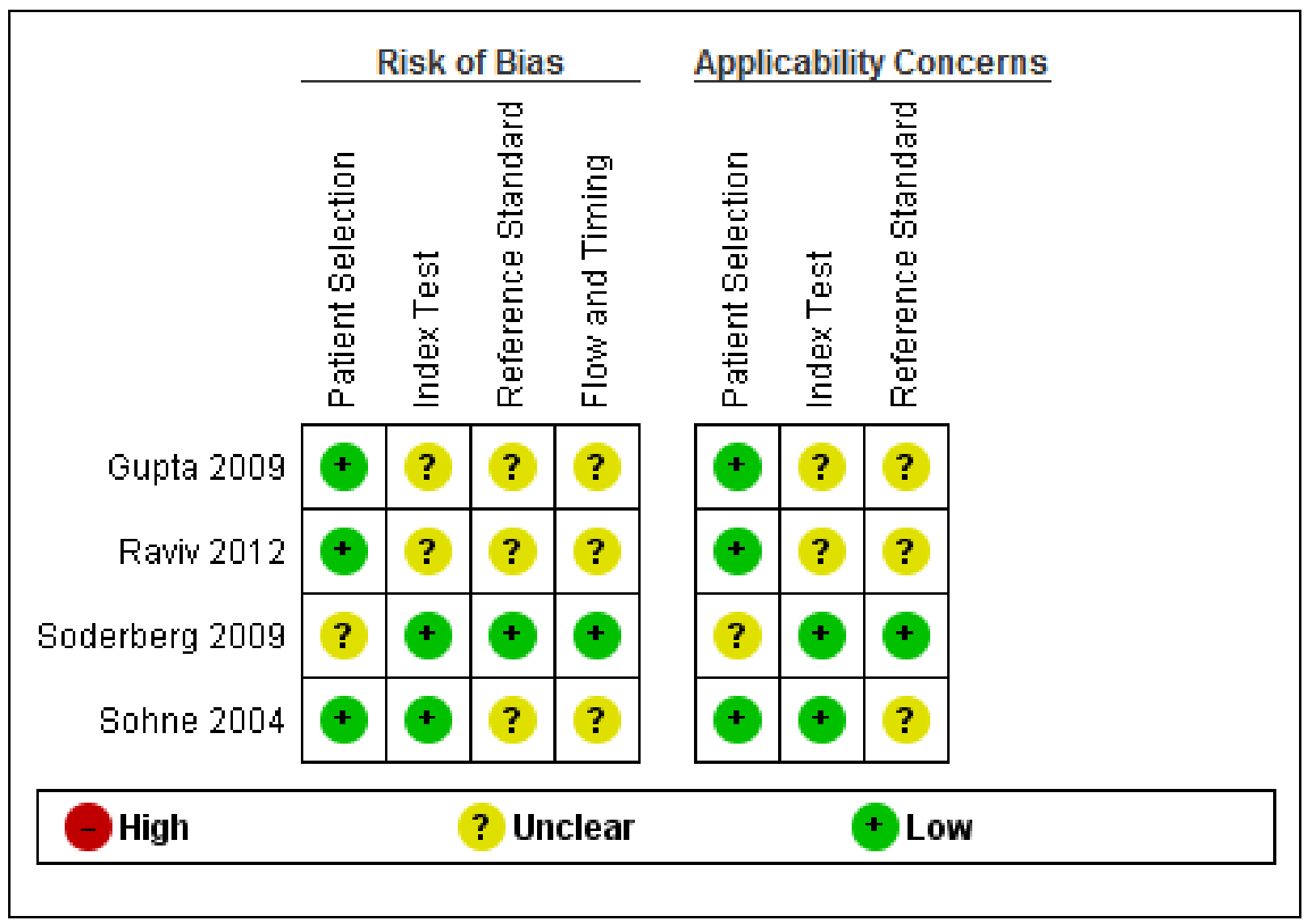

We have included four studies in the review (Gupta 2009; Raviv 2012; Soderberg 2009; Sohne 2004). The Characteristics of included studies table incorporates the methodological quality assessment. We assessed no study as having low risk of bias in all domains, but we found no instances of high risk of bias in any of the quality items. We explain below instances when we considered study quality to be at unclear risk of bias. We grouped QUADAS-2 quality assessment items into four domains: patient selection, index test, reference standard and flow and timing.

In three studies (Gupta 2009; Raviv 2012; Sohne 2004), risk of bias arising from patient selection was low, and in one study (Soderberg 2009), the risk was considered to be unclear, because although the variables used to calculate a Wells score were prospectively collected by investigators, the Wells pre-test probabilities were scored retrospectively. All four studies recruited a consecutive sample of patients with potential symptoms and signs of PE, and all included patient populations appropriate for this review question.

All four studies described the conduct of D-dimer index tests well, but two studies reported no information about the thresholds used to interpret D-dimer test results (Gupta 2009; Raviv 2012), leading to unclear risk of bias. All except one study provided a description of the reference standard (Raviv 2012), but three reports did not provide information about the way reference standard test results were interpreted (Gupta 2009; Raviv 2012; Sohne 2004).
Flow of patients and timing of the conduct of $\mathrm{D}$-dimer and reference standard tests were of greatest methodological concern; no study authors provided a flow diagram to show the flow of patients throughout their study, and only one study clearly reported the time between conduct of index and reference standard tests (Soderberg 2009). The remaining three studies (Gupta 2009; Raviv 2012; Sohne 2004) did not clearly report the timing between conduct of the index test and use of the reference standard, leading to an unclear classification of bias.

We have presented details of the conduct of D-dimer and reference standard tests in the Characteristics of included studies table.

\section{Findings}

Four studies met the eligibility criteria, and we have included them in the review (Gupta 2009; Raviv 2012; Soderberg 2009; Sohne 2004). Details of these studies can be found in the Characteristics of included studies table. Below we summarise review findings, including details of the patient population, CPRs used to calculate pre-test probability, the index test, the diagnostic threshold set by primary study authors and reference standards used to confirm the diagnosis. We have presented estimates of sensitivity and specificity that we recalculated on the basis of accuracy data from three studies (Gupta 2009; Soderberg 2009; Sohne 2004), and we have reproduced reported estimates from the fourth study (Raviv 2012). 
All D-dimer index tests evaluated were quantitative assays performed on 1585 patients.

In the study by Gupta 2009, 627 patients with clinically suspected $\mathrm{PE}$ presenting to the emergency department of a community teaching hospital had their pre-test probability of PE scored on the basis of the Geneva CPR (low clinical probability: 0 to 3 points; intermediate clinical probability: 4 to 10 points; high clinical probability: 11 points or more). Investigators used Advanced Ddimer $^{\mathrm{TM}}$ Assay (Dade Behring, Inc, Deerfield, Illinois, USA) with the diagnostic threshold set at, or above, $1.2 \mathrm{mg} / \mathrm{L}$. They confirmed the diagnosis by using computerised tomography pulmonary angiography (CTPA) as the reference standard. For patients in the low clinical probability group, sensitivity was 100\% $195 \%$ confidence interval $(\mathrm{Cl}) 61 \%$ to $100 \%$ ) and specificity was $25 \%(95 \%$ $\mathrm{Cl} 20 \%$ to $31 \%$ ). For the intermediate clinical probability group, sensitivity was $100 \%(95 \% \mathrm{Cl} 82 \%$ to $100 \%)$ and specificity $33 \%$ (95\% $\mathrm{Cl} 28 \%$ to $38 \%)$. Sensitivity and specificity were $80 \%(95 \% \mathrm{Cl}$ $38 \%$ to $96 \%)$ and $37 \%(95 \% \mathrm{Cl} 15 \%$ to $65 \%)$ for the high clinical probability group, respectively.

Raviv 2012 recruited 300 people with a suspected presentation of PE in the emergency room of a medical centre in Israel. The index test used LIA test D-di (Stago-Diagnostica, Asnieres-surSeine, France) thresholds between $800 \mathrm{ng} / \mathrm{mL}$ and $1000 \mathrm{ng} / \mathrm{mL}$ (or equivalently, $800 \mathrm{mg} / \mathrm{L}$ and $1000 \mathrm{mg} / \mathrm{L}$ were used to evaluate the accuracy of a higher D-dimer threshold) to rule out the presence of PE. A modified Wells CPR classified patient pre-test probability score as showing low or moderate risk. Most reference standard tests were angiograms, but they could take the form of other imaging tests, in particular, researchers used lung scans when patients were unable to undergo CTPA. A D-dimer threshold of $900 \mathrm{mg} / \mathrm{L}$ was reported to achieve the highest sensitivity at $94.4 \%$ and the highest specificity at $49.1 \%$. Estimates of D-dimer accuracy in patients younger than 40 years of age were reported to be higher (sensitivity $100 \%$ and specificity $54.9 \%$ ). Unfortunately, investigators provided no confidence intervals for these estimates, and the differences may have arisen by chance. We were unable to extract from the report the numbers of TPs, TNs, FPs, and FNs, and failed to obtain this information from study authors.

Soderberg 2009 recruited 120 people attending the emergency departments of two hospitals in Sweden who had a high clinical probability of $\mathrm{PE}$.. Investigators calculated pre-test probability using the Wells CPR, before using a rapid latex agglutination assay (Tinaquant ${ }^{\oplus}$, Roche, Basel, Switzerland) to measure Ddimer levels tested on a whole plasma sample. The reference standard test consisted of pulmonary angiography or CTPA, or both, performed within 48 hours of the D-dimer test, and patients received low-molecular-weight heparin at a dose of 175 to $200 \mathrm{U} / \mathrm{kg}$ subcutaneously, or unfractionated heparin 5000 IU intravenously, before reference standard investigations were performed when results of the $D$-dimer test were greater than the threshold of $<0.5$ mg L-1. Sensitivity was $91 \%(95 \% \mathrm{Cl} 81 \%$ to $97 \%)$ and specificity $63.0 \%$ ( $95 \% \mathrm{Cl} 52 \%$ to $73 \%$ ). The positive predictive value was $61 \%$, and the negative predictive value $92 \%$.

Sohne 2004 recruited hospital inpatients and outpatients to a study conducted at the Amsterdam Medical Centre in the Netherlands. General practitioners referred 538 outpatients for clinical suspicion of acute PE. Investigators used the Wells CPR to calculate pretest probability scores and included in the study those at low risk of $\mathrm{PE}$. They used a rapid immunoturbidimetric D-dimer assay (Tinaquant D-dimer ${ }^{\oplus}$, Roche Diagnostica, Mannheim, Germany) to measure D-dimer levels. The threshold for a positive D-dimer test result was $0.5 \mathrm{mg} / \mathrm{L}$, and the reference standard was a V/Q scan in combination with compression ultrasonography or pulmonary angiography. Patients with abnormal reference standard test results were considered to have PE and received treatment with anticoagulant therapy. Researchers followed up with all patients at three months, and stratified estimates of sensitivity and specificity for the outpatient population according to age. Among people aged $<65$ years, sensitivity was $100 \%(95 \% \mathrm{Cl} 97 \%$ to $100 \%)$ and specificity was $50 \%$ (95\% Cl $45 \%$ to $55 \%$ ). For individuals between 65 and 75 years of age, sensitivity was $100 \%$ (95\% Cl 85\% to 100\%) and specificity $31 \%$ (95\% Cl $20 \%$ to $44 \%$ ). For people $>75$ years of age, sensitivity was $100 \%(95 \% \mathrm{Cl} 86 \%$ to $100 \%)$ and specificity $23 \%$ ( $95 \% \mathrm{Cl} 12 \%$ to $38 \%$ ). Estimates of D-dimer accuracy based on $2 \times$ 2 data from the entire study population were $100 \%$ (95\% Cl $97 \%$ to $100 \%$ ) for sensitivity and $45 \%$ ( $95 \% \mathrm{Cl} 40 \%$ to $50 \%$ ) for specificity.

\section{DISCUSSION}

Limited evidence provided by the studies included in this review suggests that quantitative D-dimer tests used in emergency departments result in few false-negatives but very high levels of false-positive results, with a high level of sensitivity consistently evident across all age groups. This makes the test useful as a rule-out test but means that a positive result will require further investigation with diagnostic imaging test(s).

All four studies reviewed reported high numbers of false-positives. We found specificity to be lower among those over the age of 65 years in one study, and it appeared to decrease as patient age increased, but this finding did not reach statistical significance (Sohne 2004): D-dimer assays have been shown to possess lowest specificity in those over 75 years of age, for whom the natural D-dimer concentration is expected to be higher (Schreiber 2002). The poor specificity of D-dimer has long been a concern of those diagnosing pulmonary embolism (PE) who are keen to find a cheap, quick and simple-to-use alternative to resourceintensive diagnostic imaging tests and their potential adverse effects (Kabrhel 2006).

Authors of another systematic review evaluating the performance of D-dimer assays in older patients with suspected venous thromboembolism (VTE), which included some patients with PE (Schouten 2013), reported age-related false-positive results. Data from 13 cohorts of patients with VTE $(n=12,630)$, none of which met the eligibility criteria for this review, showed an increase in the number of false-positives with increasing age.

It has been suggested that one solution might be to use a higher threshold for interpretation of D-dimer test results to improve its specificity in older age groups. Unfortunately, we found no evidence to support this suggestion; of the two studies with the highest concentration thresholds of D-dimer, one did not present accuracy data according to patient age (Gupta 2009), and we were unable to extract accuracy data (true-positive (TP), true-negative (TN), false-positive (FP) and false-negative (FN)) data from the other study (Raviv 2012).

Only one study included patients with high pre-test probability (PTP) scores (Gupta 2009); in this group, sensitivity was $80 \%$, compared with $100 \%$ in those with low or intermediate PTP. 
The proportion of disease-positive patients (prevalence) varied among different patient groups within studies and across studies. It has been suggested that differences in the prevalence of disease among populations can affect the accuracy of a test, but this does not appear to have influenced test accuracy in this circumstance (Leeflang 2009).

We were unable to perform a meta-analysis of $2 \times 2$ data because of the small number of identified studies $(n=4)$, and we would advise against over-interpretation of review findings.

Data from the studies included in our review show that dimer assays can rule out PE, but the low specificity of positive tests means that further research to try to refine the testing pathway is merited, especially in older age groups. Healthcare professionals working in emergency departments should be aware that using the D-dimer test to rule out PE in older people may not lead to a reduction in the ordering of other, more expensive tests. Therefore, the cost-effectiveness of the diagnostic pathway deserves consideration by those designing future research studies.

\section{Summary of main results}

We have tabulated a summary of the main results from this review in Summary of findings 1.

\section{Strengths and weaknesses of the review}

The strength of this review is the adoption of high methodological standards, in particular, screening of 4870 records and detailed scrutiny of 54 studies allowed us to make important recommendations for future research about the diagnostic accuracy of D-dimer for excluding PE in outpatient and emergency patient populations. These recommendations relate to both the methodological conduct of future studies and the clinical question that remains unanswered.

Weaknesses of the review include the small number of included eligible studies, data from which were unsuitable for pooling in a meta-analysis. Key differences between studies include differences between clinical prediction rules (CPRs), D-dimer assays and thresholds used.

\section{Applicability of findings to the review question}

The findings of this review are applicable to the review question, but in some included studies, information about interpretation of index and reference standard test results is lacking, as are details of the time period between administration of index and reference standard tests. A high proportion of studies identified by our search did not meet the eligibility criteria of the review, and we therefore excluded them (Characteristics of excluded studies). In most cases, we excluded studies because they did not include in the analysis all patients who had a D-dimer test (e.g. all patients with a positive test result), or they did not report reference standard test results for all patients. These methodological weaknesses could result in bias and over-estimation of the accuracy of the test. Another common reason for exclusion was the omission of a CPR in the diagnostic pathway used to assess study patients' pre-test probability. As this is standard clinical practice, we considered use of a CPR an essential component of included studies, to ensure that findings of the review were applicable to the review question and informative of the usual diagnostic pathways found in routine clinical practice.

\section{AUTHORS' CONCLUSIONS}

\section{Implications for practice}

A negative $D$-dimer is useful in ruling out $P E$ in patients who do not have a high PTP of PE, but its clinical utility may diminish in older people.

\section{Implications for research}

Well-designed studies are needed to evaluate whether the specificity of D-dimers can be improved without loss of sensitivity. The diagnostic accuracy of interpretation of D-dimer test results using higher thresholds in older patients is especially necessary, as has been reported by others (Penaloza 2012). Future studies of the diagnostic accuracy of D-dimer should contain analyses stratified according to the different age groups of patients studied. Separate analyses of patients based on their scores from CPRs would also be directly applicable to clinical decision making. Methodologically, we suggest that all patients who receive a pre-test probability score followed by a D-dimer test should have accuracy verified with a reference standard test, and $2 \times 2$ data should be reported for the whole study population. Future investigators should clearly report details of the manner in which all test (index and reference standard) results are interpreted and the timing of administration of index and reference standard tests.

\section{ACK N O WLEDGEMEN TS}

This review forms part of work funded by a National Institute of Health Research (NIHR) Cochrane Programme Grant. 


\section{RE F E R E N C E S}

\section{References to studies included in this review}

Gupta 2009 \{published data only\}

Gupta RT, Kakarla RK, Kirshenbaum KJ, Tapson VF. D-Dimer and efficacy of clinical risk estimation algorithms: sensitivity in evaluation of acute pulmonary embolism. American Journal of Roentgenology 2009;193:425-30.

Raviv 2012 \{published data only\}

Raviv B, Israelit SH. Shifting up cut-off value of D-dimer in the evaluation of pulmonary embolism: a viable option? Possible risks and benefits. Emergency Medicine International 2012;2012:Article ID 517375 (6 pages). [DOI: $10.1155 / 2012 / 517375$

\section{Soderberg 2009 \{published data only\}}

Soderberg M, Brohult J, Jorfeldt L, Larfars G. The use of d-dimer testing and Wells score in patients with high probability for acute pulmonary embolism. Journal of Evaluation in Clinical Practice 2009;15:129-33.

\section{Sohne 2004 \{published data only\}}

Sohne M, Kamphuisen PW, van Mierlo PJWB, Buller HR. Diagnostic strategy using a modified clinical decision rule and D-dimer test to rule out pulmonary embolism in elderly in-and outpatients. Thrombosis and Haemostasis 2005;94:206-10.

\section{References to studies excluded from this review}

\section{Barsotti 1987 \{published data only\}}

Barsotti A, Savarino A. Evaluation of a latex test for D-dimer fibrinogen/fibrin determination [Valutazione di un test al lattice per la determinazione del dimero d del fibrinogeno/fibrina (XDP)]. Quaderni Sclavo di Diagnostica Clinica e di Laboratorio 1987;23:421-4.

\section{Bounameaux 1988 \{published data only\}}

Bounameaux H, Slosman D, de Moerloose PH, Reber G. Diagnostic value of plasma D-dimer in suspected pulmonary embolism. Lancet 1988;2(8611):628-9.

\section{Bounameaux 1991 \{published data only\}}

Bounameaux H, Cirafici P, de Mooreloose P, Schnieder PA Slosman D, Reber G, et al. Measurement of D-dimer in plasma as diagnostic aid in suspected pulmonary embolism. Lancet 1991;337:196-200.

Reber G, Vissac A-M, de Moerloose P, Bounameaux H, Amiral J. A new semi-quantitative and individual ELISA for rapid measurement of plasma D-dimer in patients suspected of pulmonary embolism. Blood Coagulation and Fibrinolysis 1995;6:460-3.

\section{Bounameaux 1992 \{published data only\}}

Bounameaux $\mathrm{H}$. Value of the measurement of plasma D-dimers in venous thromboembolic disease [Interet du dosages des D-dimeres dans la maladie thrombo-embolique veineuse]. Journal des Malades Vasculaires 1992;17:91-2.

\section{Christopher Study \{published data only\}}

Nijkeuter M, Tick LW, Sohne M, Kruip MJHA, Buller HR, Leebeck FWG, et al. on behalf of the Christopher Study Investigators. Excluding pulmonary embolism without imaging tests - Can our diagnostic algorithm be optimized?. Thrombosis Haemostasis 2008;100:1203-6.

van Belle A, Büller HR, Huisman MV, Huisman PM, Kaasjager K, Kamphuisen PW, et al. Effectiveness of managing suspected pulmonary embolism using an algorithm combining clinical probability, D-dimer testing and computed tomography. JAMA 2006;295(2):172-9.

\section{Courtney 2008 \{published data only\}}

Courtney DM, Steinberg JM, McCormick J. Prospective diagnostic accuracy assessment of the HemosIL HS D-dimer to exclude pulmonary embolism in emergency patients. Thrombosis Research 2010;125:79-83.

deBastos 2008 \{published data only\} deBastos MM, Bastos MRD, Pessoa PCH, Bogutchi T, CarneiroProietti ABF, Rezende S. Managing suspected venous thromboembolism in a mixed primary and secondary care setting using standard clinical assessment and D-dimer in a noninvasive diagnostic strategy. Blood Coagulation and Fibrinolysis 2008;19:48-54.

\section{Demers 1992 \{published data only\}}

Demers C, Ginsberg JS, Johnston M, Brill-Edwards P, Panju A. D-dimer and thrombin-antithrombin III complexes in patients with clinically suspected pulmonary embolism. Thrombosis and Haemostasis 1992;67:408-12.

\section{de Moerloose 1996 \{published data only\}}

de Moerloose P, Desmarais S, Bounameaux H, Reber Perrier A, Dupuy G, Pittet J-L. Contribution of a new, rapid individual and quantitative automated d-dimer ELISA to exclude pulmonary embolism. Thrombosis and Haemostasis 1996;75(1):11-3.

Djurabi 2009 \{published data only\}

Djurabi RK, Klok FA, Nijkeuter M, Kamphuisen PW, Kramer MHH, Kruip MJHA, et al. Comparisin of the clinical usefulness of two quantitative D-dimer tests in patients with a low clinical probability of pulmonary embolism. Thrombosis Research 2009;123:771-4.

\section{Douma 2011 \{published data only\}}

Douma RA, Mos ICM, Erkens PMG, Nizet TAC, Durian MF, Hovens MM, et al. Performance of 4 clinical decision rules in the diagnostic management of acute pulmonary embolism. Annals of Internal Medicine 2011;154(11):709-18.

van Es J, Beenen LFM, Gerdes VEA, Middeldorp S, Douma RA, Bossuyt PMM. The accuracy of D-dimer testing in suspected pulmonary embolism varies with the Wells score. Journal of Haemostasis 2012;10:2630-2. 
Eilas 2005 \{published data only\}

Eilas A, Cazanave A, Eilas M, Chabbert V, Juchet H, Paradis $\mathrm{H}$, et al. Diagnostic management of pulmonary embolism using clinical assessment, plasma D-dimer assay, complete lower limb venous ultrasound and helical computed tomography of pulmonary arteries. Thrombosis and Haemostasis 2005;93:982-8.

\section{Faivre 1990 \{published data only\}}

Faivre R. Prognostic value of D-dimers. La Presse Medicale 1990;19:2038-9.

\section{Friera-Reyes 2005 \{published data only\}}

Friera-Reyes A, Caballero P, Ruiz-Giménez N, Artieda P, Domínguez L, Pérez-Amor E, et al. Usefulness of fast ELISA determination of $D$-dimer levels for diagnosing pulmonary embolism in an emergency room. Archives of Bronconeumologia 2005;41(9):499-504.

\section{Gavaud 1996 \{published data only\}}

Gavaud C, Ninet J, Ville D, Cpere B, Hanss M, Bureau Du Colombier $\mathrm{P}$, et al. Dosage of the D-dimers in the diagnosis of deep vein thrombosis and/or pulmonary embolism. EReview based on 80 consecutive patients seen in an emergency unit. [Le diagnostic de la thromboses veineuse et/ou de l'embolie pulmonaire par le dosages des d-dimeres Elisa]. Journal des Malades Vasculaires 1996;21:22-30.

\section{Geersing 2012 \{published data only\}}

Geersing GJ, Erkens PMG, Lucassen WAM, Buller HR, ten Cate H, Hoes AWH, et al. Safe exclusion of pulmonary embolism using the Wells rule and qualitative $\mathrm{D}$-dimer testing in primary care: prospective cohort study. BMJ 2012;345:e6564.

\section{Ghanima 2005 \{published data only\}}

Ghanima W, Abdelnoor M, Mowinckel M-C, Sandset PM. The performance of STA-Liatest D-dimer assay in outpatients with suspected pulmonary embolism. British Journal of Haematology 2005;132:210-5.

\section{Ghanima 2007 \{published data only\}}

Ghanima W, Sandset PM. Validation of a new D-dimer microparticle enzyme immunoassay (AXSYM) in patients with suspected pulmonary embolism (PE). Thrombosis Research 2007;120:471-6.

\section{Goekoop 2007 \{published data only\}}

Goekoop A, Werker-van Gelder L, Vlasveld LT, van Klink RCJ, Planken EV, Huisman MV. Simple and safe exclusion of pulmonary embolism in outpatients using quantitative D-dimer and Well's simplified decision rule. Thrombosis and Haemostasis 2007;97:146-50.

\section{Harper 2007 \{published data only\}}

Harper PL, Theakston E, Ahmed J, Ockelford P. D-dimer concentration increases with age reducing the clinical value of the D-dimer assay in the elderly. Internal Medicine 2007;37:607-13.

\section{Hirai 2007 \{published data only\}}

Hirai LK, Takahashi JM, Yoon HC. A prospective evaluation of a quantitative $D$-dimer assay in the evaluation of acute pulmonary embolism. Journal of Vascular Radiology 2007;18:970-4.

\section{Hochuli 2007 \{published data only\}}

Hochuli M, Duewell S, Frauchiger. Quantitative D-dimer levels and the extent of venous thromboembolism in CT angiography and lower limb ultrasonography. VASA 2007;36:267-74.

\section{Hogg 2005 \{published data only\}}

Hogg K, Dawson D, Mackway-Jones K. The emergency department utility of Simplify D-dimer to exclude pulmonary embolism in patients with pleuritic chest pain. Annals of Emergency Medicine 2005;46:305-10.

\section{Kabrhel 2007 \{published data only\}}

Kabrhel C. Outcomes of high pretest probability patients undergoing D-dimer testing for pulmonary embolism: a pilot study. Journal of Emergency Medicine 2008;35(4):373-7.

\section{Kline 1997 \{published data only\}}

Kline JA, Meek S, Boudrow D, Warner D, Colucciello S. Use of the alveolar dead space fraction (Vd/Vt) and plasma D-dimers to exclude acute pulmonary embolism in ambulatory patients. Academic Emergency Medicine 1997;4:856-63.

Kline 2002 \{published data only\}

Kline JA, Nelson RD, Jackson RE, Courtney DM. Criteria for the safe use of D-dimer testing in emergency department patients with suspected pulmonary embolism: a multi centre study. Annals of Emergency Medicine 2002;38(2):144-50.

Kline 2006 \{published data only\}

Kline JA, Runyon MS, Webb WB, Jones AE, Mitchell AM. Prospective study of the diagnostic accuracy of the Simplify Ddimer assay for pulmonary embolism in emergency department patients. Chest 2006;129:1417-23.

\section{Kovacs 2001 \{published data only\}}

Kovacs MJ, MacKinnon KM, Anderson D, O'Rourke K, Keeney M, Kearon C, et al. A comparison of three rapid d-dimer methods for the diagnosis of venous thromboembolism. British Journal of Haematology 2001;115:140-4.

\section{Laaban 1997 \{published data only\}}

Laaban J-P, Achkar A, Horellou M-H, Conard J, Bouarfa N, Akram $R$, et al. Usefulness of measuring plasma d-dimers for diagnosis of acute venous thrombo-embolism [Interet du dosages des D-dimeres plasmatiques dans le diagnostic des accidents thrombo-emboliques veineux]. Revue des Maladies Respiratoires 1997;14:119-27.

\section{LeGal 2006 \{published data only\}}

LeGal G, Righini M, Roy P-M, Sancjez O, Aujesky D, Perrier A, et al. Value of D-dimer testing for the exclusion of pulmonary embolism in patients with previous venous thromboembolism. Archives of Internal Medicine 2006;166:176-80. 
Legani 2009 \{published data only\}

Legnani C, Cini M, Scarvelis D, Toulon P, Wu JR, Palareti G. Multicentre evaluation of a new quantitative highly sensitive Ddimer assay. Thrombosis Research 2010;125:398-401.

\section{Lucassen 2010 \{published data only\}}

Lucassen WAM, Douma RA, Toll DB, Buller HR, van Weert HCPM. Excluding pulmonary embolism in primary care using the Wellsrule in combination with a point-of-care D-dimer test: a scenario analysis. BMC Family Practice 2010;11:64

\section{Lucassen 2013 \{published data only\}}

Lucassen W, Erkens P, Geersing G-J. Diagnosis of lung embolism. Huisarts Wet 2013;56(6):264-8.

\section{Parent 2007 \{published data only\}}

Parent F, Maitre S, Meyer G, Raherison C, Mal H, Lancar R, et al. Diagnostic value of $D$-dimer in patients with suspected pulmonary embolism: results from a multicentre outcome study. Thrombosis Research 2007;120:195-200.

Park 2008 \{published data only\}

Park R, Seo YI, Yoon SG, Choi TY, Shin JW, Uh ST, et al. Utility of $D$-dimer assay for diagnosing pulmonary embolism: single institute study. Korean Journal of Laboratory Medicine 2008;28:419-24.

\section{Perrier 1996 \{published data only\}}

Perrier A, Bounameaux H, Morabia A, de Moerloose P, Slosman $D$, Didier $D$, et al. Diagnosis of pulmonary embolism by a decision analysis-based strategy including clinical probability, d-dimer levels, and ultrasonography: a management study. Archives of Internal Medicine 1996;156:531-5.

\section{Perrier 1997 \{published data only\}}

Perrier A, Desmarais S, Goehring C, de Moerloose P, Morabia A, Unger P-F, et al. D-dimer testing for suspected pulmonary embolism in outpatients. American Journal of Respiratory Critical Care 1997;156:492-6.

\section{Ray 2006 \{published data only\}}

Ray P, Bellick B, Birolleau S, Marx J-S, Arock M, Riou B. Referent D-dimer enzyme-linked immunosorbent assay testing is of limited value in the exclusion of thromboembolic disease: result of a practical study in an ED. American Journal of Emergency Medicine 2006;24:313-8.

\section{Reber 2007 \{published data only\}}

Reber G, Boehlen F, Bounameaux H, De Moerloose P. Performance of the AxSYM D-dimer assay for the exclusion of pulmonary embolism. Journal of Thrombosis and Haemostasis 2007;5:2304-5

\section{Righini 2004 \{published data only\}}

Righini M, Aujesky D, Roy P-M, Cornuz J, de Moerloose P, Bounameaux $\mathrm{H}$, et al. Clinical usefulness of D-dimer depending on clinical probability and cutoff value in outpatients with suspected pulmonary embolism. Archives of Internal Medicine 2004;164:2483-7.

\section{Scarvelis 2008 \{published data only\}}

Scarvelis D, Palareti G, Toulon P, Wells PS, Wu JR. HemosIL Ddimer HS assay in the diagnosis of deep vein thrombosis and pulmonary embolism. Results of a multicentre management study. Thrombosis and Haemostasis 2008;6:1973-5.

\section{Sebestyen 1990 \{published data only\}}

Sebestyen G, Quillet P, Cambres C. Measurement of fibrinopeptide $A(\mathrm{FpA})$ : comparison between an enzymatic and an isotopic methodology [Dosage du fibrinopeptide $A(F p A)$ : comparaison d'une methode enzymatique et d'une methode isotopique en reference a la scintigraphe de ventilationperfusion]. Annales de Biologie Clinique 1990;48:161-4.

Soo Hoo 2011 \{published data only\}

Soo Hoo GW, Wu CC, Vazirani S, Zhaoping L, Barack BM. Does a clinical decision rule using $\mathrm{d}$-dimer level improve the yield of pulmonary CT angiography?. AJR 2011;196:1059-64.

\section{Soons 2000 \{published data only\}}

Soons JWPH. D-dimer for the diagnosis for the exclusion of lung embolism. Nederlands Tijdschrift voor Klinische Chemie 2000;25:288-92.

\section{Than 2009 \{published data only\}}

Than MP, Helm J, Calder K, Ardagh MW, Smith M, Flaws DF, et al. Comparison of high specificity with standard versions of a quantitative latex D-dimer test in the assessment of community pulmonary embolism HaemosIL D-dimer HS and pulmonary embolism. Thrombosis Research 2009;124:230-5.

\section{Waser 2005 \{published data only\}}

Waser G, Kathriner S, Wuillemin WA. Performance of the automated and rapid STA Liatesat D-dimer on the STA-R analyzer. Thrombosis Research 2005;116:165-70.

\section{Yamaki 2007 \{published data only\}}

Yamaki T, Nozaki M, Sakurai H, Takeuchi M, Soejma K, Kono T. Uses of different $D$-dimer levels can reduce the need for venous duplex scanning to rule out deep vein thrombosis in patients with symptomatic pulmonary embolism. Journal of Vascular surgery 2007;46:526-32.

\section{References to studies awaiting assessment}

Ahamad 2000 \{published data only\}

Ahamad S, Cella G, Hoppensteadt D, Jeske W, Kaiser B, Kaiser W. Deep vein thrombosis. Phleblymphology 2000;30:35-48.

Undurrage 2001 \{published data only\}

Undurraga PA, Pereira A. Diagnosis of pulmonary embolism [Diagnostico del tromboembolismo pulmonar]. Revista Chilena de Enfermedades Respiratorias 2001;17(1):43-6.

\section{Additional references}

Ainish 1999

Ainish EJ, Mayewski RJ. Chapter 28: Respiratory problems. Pulmonary embolism. In: Black ER, Bordley DR, Tape TG, Panzer RJ editor(s). Diagnostic Strategies for Common Medical 
Problems. 2nd Edition. Philadelphia: American College of Physicians, 1999:325.

\section{Andras 2012}

Andras A, Sala Tenna A, Crawford F. Vitamin K antagonists or low-molecular-weight heparin for the long term treatment of symptomatic venous thromboembolism. Cochrane Database of Systematic Reviews 2012, Issue 10. [DOI: 10.1002/14651858.CD002001.pub2]

\section{Becker 1996}

Becker DM, Philbrick JT, Bachhuber TL, Humphries JE. D-dimer testing and acute venous thromboembolism: a shortcut to accurate diagnosis?. Archives of Internal Medicine 1996;156(9):939-46.

\section{Ceriani 2010}

Ceriani E, Combescure C, Le Gal G, Nendaz M, Perneger T, Bounameaux $\mathrm{H}$, et al. Clinical prediction rules for pulmonary embolism: a systematic review and meta analysis. Journal of Thrombosis and Haemostasis 2010;8(5):957-70.

\section{Deeks 2005}

Deeks JJ, Macaskill P, Irwig L. The performance of tests of publication bias and other sample size effects in systematic reviews of diagnostic test accuracy was assessed. Journal of Clinical Epidemiology 2005;58:882-93.

\section{Di Nisio 2007}

Di Nisio M, Squizzato A, Rutjes AW, Büller HR, Zwinderman AH, Bossuyt PM. Diagnostic accuracy of D-dimer test for the exclusion of venous thromboembolism: a systematic review. Journal of Thrombosis and Haemostasis 2007;5(2):296-304.

\section{Goldhaber 1998}

Goldhaber SZ. Pulmonary embolism. The New England Journal of Medicine 1998;339(2):93-104.

\section{Goodacre 2006}

Goodacre S, Sampson F, Stevenson M, Wailoo A, Sutton A, Thomas $S$, et al. Measurement of the clinical and cost effectiveness of non-invasive diagnostic testing strategies for deep vein thrombosis. Health Technology Assessment May 2006;10(15):1-168, iii-iv.

\section{Harbord 2007}

Harbord RM, Deeks JJ, Egger M, Whiting P, Sterne JAC. A unification of models for meta analysis of diagnostic accuracy studies. Biostatistics 2007;8(2):239-51.

\section{Kabrhel 2006}

Kabrhel C, Matts C, McNamara M, Katz J, Ptak T. A highly sensitive ELISA D-dimer increases testing but not diagnosis of pulmonary embolism. Academic Emergency Medicine 2006;13:519-24.

\section{Laupacis 1997}

Laupacis A, Sekar N, Stiell IG. Clinical prediction rules: a review and suggested modifications of methodological standards. JAMA 1997;277:488-94.

\section{Leeflang 2009}

Leeflang MMG, Bossuyt PMM. Diagnostic test accuracy may vary with prevalence: implications for evidence-based diagnosis. Journal of Clinical Epidemiology 2009;62:5-12.

\section{NCGC 2012}

National Guideline Centre. Venous thromboembolic diseases: the management of venous thromboembolic diseases and the role of thrombophilia testing. http://www.nice.org.uk/ guidance/CG144, 2012 (accessed 23 July 2016).

\section{Penaloza 2012}

Penaloza A, Roy PM, Kline J, Verschuren F, Le Gal G, QuentinGeorget S, et al. Performance of age-adjusted D-dimer cut-off to rule out pulmonary embolism. Journal of Thrombosis and Haemostasis 2012;10:1291-6.

\section{PRISMA 2009}

Moher D, Liberati A, Tetzlaff J, Altman DG, PRISMA Group. Preferred reporting items for systematic reviews and meta-analyses: the PRISMA statement. PLoS Medicine 2009;6(7):e1000097.

\section{Revel 2012}

Revel MP, Sancez O, Couchon S, Planquette B, Hernigou A, Niarra R, et al. Diagnostic accuracy of magnetic resonance imaging for acute pulmonary embolism: results of the "IRM-EP" study. Journal of Thrombosis and Haemostasis 2012;5:743-50.

\section{Rutjes 2005}

Rutjes AWS, Reitsma JB, Vandenbrouke JP, Glas AS, Bossuyt PMM. Case-control and two-gate designs in diagnostic accuracy studies. Clinical Chemistry 2005;51(8):1335-41.

\section{Schouten 2013}

Schouten HJ, Geersing GJ, Koek HL, Zuithoff NPA, Janssen KJM, Douma RA, et al. Diagnostic accuracy of conventional or age adjusted D-dimer cut-off values in older patients with suspected venous thromboembolism: systematic review and metaanalysis. BMJ 2013;346:f2492.

\section{Schrecengost 2003}

Schrecengost JE, LeGallo RD, Boyd JC, Moons KG, Gonias SL, Rose CE Jr, et al. Comparison of diagnostic accuracies in outpatients and hospitalised patients of D-dimer testing for the evaluation of suspected pulmonary embolism. Clinical Chemistry 2003;49(9):1483-90.

\section{Schreiber 2002}

Schreiber DH. The role of D-dimer in the diagnosis of venous thromboembolism. Laboratory Medicine 2002;33(2):136-41.

\section{Smidt 2008}

Smidt N, Deeks J, Moore T (editors). Chapter 4: Guide to the contents of a Cochrane review and protocol for diagnostic test accuracy. In: Cochrane Diagnostic Test Accuracy Working Group, editor. Cochrane Handbook for Diagnostic Test Accuracy Reviews [in press]: The Cochrane Collaboration; 2008. www.cochrane-handbook.org (http://srdta.cochrane.org/en/ authors.html). 


\section{van Belle 2006}

van Belle A, Büller HR, Huisman MV, Huisman PM, Kaasjager K, Kamphuisen PW, et al. Effectiveness of managing suspected pulmonary embolism using an algorithm combining clinical probability, D-dimer testing and computed tomography. JAMA 2006;295(2):172-9.

\section{Wells 1997}

Wells PS, Anderson DR, Bormanis J, Guy F, Mitchell M, Gray L, et al. Value of assessment of pretest probability of deep vein thrombosis in clinical management. Lancet 1997;350(9094):1795-8.

\section{Wells 2006}

Wells PS, Owen C, Doucette S, Ferguson D, Tran H. Does this patient have deep vein thrombosis?. JAMA 2006;295(2):199-207.

\section{Wells 2007}

Wells PS. Integrated strategies for the diagnosis of venous thromboembolism. Journal of Thrombosis and Haemostasis 2007;5 Suppl 1:41-50.

\section{CHARACTERISTICS OF STUDIES}

Characteristics of included studies [ordered by study ID]

\section{White 2003}

White RH. The epidemiology of venous thromboembolism. Circulation 2003;107(23 Suppl 1):14-8.

\section{Whiting 2011}

Whiting PF, Rutjes AW, Westwood ME, Mallett S, Deeks JJ, Reitsma JB, et al. QUADAS-2: a revised tool for the quality assessment of diagnostic accuracy studies. Annals of Internal Medicine 2011;155(8):529-36.

\section{Yoo 2012}

Yoo HHB, Queluz THAT, El Dib R. Anticoagulant treatment for subsegmental pulmonary embolism. Cochrane Database of Systematic Reviews 2014, Issue 4. [DOI: 10.1002/14651858.CD010222.pub2]

\section{References to other published versions of this review Crawford 2013}

Crawford F, Andras A, Welch K, Sheares K, Keeling D, Chappell FM. D-dimer test for excluding the diagnosis of pulmonary embolism. Cochrane Database of Systematic Reviews 2013, Issue 12. [DOI: 10.1002/14651858.CD010864]

\section{Gupta 2009}

\section{Study characteristics}

\begin{tabular}{ll}
\hline Patient sampling & Cross-sectional study \\
\hline $\begin{array}{l}\text { Patient characteristics } \\
\text { and setting }\end{array}$ & $\begin{array}{l}627 \text { patients; men } \mathrm{n}=213(34 \%) \text {; women } \mathrm{n}=414 \text { (66\%). Mean age was } 46.9 \text { years (range 15 to 94). The } \\
\text { study was conducted at a 500-bed community teaching hospital }\end{array}$ \\
& $\begin{array}{l}\text { Inclusion criteria: arrival to the emergency department with clinically suspected PE; acute onset of new } \\
\text { or worsening dyspnoea or chest pain without another obvious cause. D-dimer assay and pulmonary CTA }\end{array}$ \\
& $\begin{array}{l}\text { Exclusion criteria Patients were excluded from the study if they had renal insufficiency, were pregnant or } \\
\text { chose not to undergo pulmonary CT }\end{array}$ \\
& $\begin{array}{l}\text { Patients had their pre-test probability calculated with the Geneva CPR as follows: low clinical probabil- } \\
\text { ity: } 0 \text { to } 3 \text { points; intermediate clinical probability: } 4 \text { to } 10 \text { points; high clinical probability: } 11 \text { or more } \\
\text { points }\end{array}$
\end{tabular}

Index tests

The index test was a quantitative D-dimer assay (Advanced D-dimer ${ }^{\mathrm{TM}}$, Dade Behring, Inc, Deerfield, Illinois, USA), an automated latex enhanced immunoturbidimetric assay. The assay was performed with a Sysmex CA-1500 instrument (Sysmex America). $1.2 \mathrm{mg} / \mathrm{L}$ was the NVP cutoff for VTE and PE. The threshold was $1.2 \mathrm{mg} / \mathrm{L}$ - the standard threshold at the study authors' institution. Patients received $100 \mathrm{~mL} / \mathrm{s}$ of iopamidol (Isovue 370, Bracco) at a rate of $4 \mathrm{~L} / \mathrm{s} \mathrm{IV.} 50$ millilitres of normal saline solution was flushed IV after contrast administration

Target condition and reference standard(s)
The target condition was clinically suspected $\mathrm{PE}$. The reference standard was pulmonary computerised tomography. Pulmonary CTA was performed with 16 MDCT scanner. All scans were acquired at 1-mm section thickness. Imaging was performed approximately 15 to 20 seconds after contrast IV. Determined with precise contrast tracking system (SureStart Toshiba Medical Systems). All readings of pulmonary CTA scans were rendered by a board-certified radiologist with 2 to 20 years' experience 
Gupta 2009 (Continued)

Flow and timing Timing between the index test and the reference standard test was not reported

\section{Comparative}

Notes

\section{Methodological quality}

\begin{tabular}{llll}
\hline Item & Authors' judgement & Risk of bias & Applicability concerns
\end{tabular}

\section{DOMAIN 1: Patient Selection}

Was a consecutive or ran- Yes

dom sample of patients

enrolled?

Was a case-control de- Yes

sign avoided?

Did the study avoid inap- Yes

propriate exclusions?

Low

Low

\section{DOMAIN 2: Index Test All tests}

If a threshold was used, Yes

was it pre-specified?

\begin{tabular}{lll}
\hline & Unclear & Unclear \\
\hline DOMAIN 3: Reference Standard & & \\
\hline $\begin{array}{l}\text { Is the reference stan- } \quad \text { Yes } \\
\text { dards likely to correctly } \\
\text { classify the target condi- }\end{array}$ & & \\
tion? & Unclear & Unclear \\
\hline
\end{tabular}

\section{DOMAIN 4: Flow and Timing}

Was there an appropriate Unclear

interval between index

test and reference stan-

dard?

Were all patients includ- Yes

ed in the analysis?

\section{Unclear}

\section{Raviv 2012}

\section{Study characteristics}

D-dimer test for excluding the diagnosis of pulmonary embolism (Review) 
Raviv 2012 (Continued)

Patient sampling

Retrospective cross-sectional study conducted between 01/01/2010 and 30/10/2010

Patient characteristics and setting

300 patients; males $n=112(37.34 \%)$, females $n=188(62.66 \%)$. Mean age of females was $54.38 \pm 19.6$ years and of males $53.7 \pm 17.60$ years

Inclusion criteria: patients with suspected clinical presentation of PE and with low or intermediate pre-test clinical probability of PE calculated with a modified Wells CPR

Exclusion criteria: Patients with a high probability based on the Wells score were drawn out of the study, as they were not candidates for D-dimer testing according to the guidelines. Patients for whom evaluation was incomplete or for whom any required data were insufficient were also excluded

Patients with suspected clinical presentation of PE were recruited from the emergency room of BamBam Medical Centre, Northern Israel

Index tests

LIA test D-di (Stago Diagnostica, Asnieres-sur-Seine, France) thresholds between $800 \mathrm{ng} / \mathrm{mL}$ and $1000 \mathrm{ng} / \mathrm{mL}$ were used to determine the most appropriate D-dimer value that study authors regarded as "standard"

Target condition and refer- $\quad$ The reference standard was reported as "imaging studies - default angiograms" ence standard(s)

Flow and timing Timing between index and reference standard tests was not reported

Comparative

Notes Patients were stratified according to age as follows: 65 years and older, 40 to 65 years old, younger than 40 years. A linear relationship was noted between patient age and D-dimer values, and a statistically significant difference in D-dimer levels was observed between the older patient group and each of the other groups

Methodological quality

\begin{tabular}{llll}
\hline Item & Authors' judgement & Risk of bias & Applicability concerns \\
\hline
\end{tabular}

DOMAIN 1: Patient Selection

Was a consecutive or random Yes sample of patients enrolled?

Was a case-control design Yes avoided?

Did the study avoid inappro- Yes priate exclusions?

Low Low

\section{DOMAIN 2: Index Test All tests}

If a threshold was used, was Yes

it pre-specified?

Unclear

Unclear

\section{DOMAIN 3: Reference Standard}


Raviv 2012 (Continued)

Is the reference standards likely to correctly classify the target condition?

\begin{tabular}{lll}
\hline & Unclear & Unclear \\
\hline DOMAIN 4: Flow and Timing & &
\end{tabular}

Was there an appropriate in- Unclear
terval between index test and

reference standard?

Were all patients included in Yes

the analysis?

\section{Unclear}

\section{Soderberg 2009}

\section{Study characteristics}

\begin{tabular}{|c|c|}
\hline Patient sampling & Prospective cross-sectional study \\
\hline \multirow[t]{3}{*}{$\begin{array}{l}\text { Patient characteristics } \\
\text { and setting }\end{array}$} & $\begin{array}{l}120 \text { patients; } n=43 \text { men, } n=77 \text { women. Mean age of people with PE was } 57 \text { years (range } 27 \text { to } 80 \text { ), mean } \\
\text { age of people without } P E 57 \text { years (range } 20 \text { to } 80 \text { ). Clinical signs and symptoms of } P E \text {, high clinical suspi } \\
\text { cion of } P E \text {, Wells pre-test probability score calculated from patient }\end{array}$ \\
\hline & $\begin{array}{l}\text { medical notes retrospectively, with } 4.0 \text { or more points considered high risk. Data for scores of } 3 \text { and } 6 \\
\text { were also analysed }\end{array}$ \\
\hline & $\begin{array}{l}\text { Inclusion criteria: high clinical suspicion of PE and clinical signs and symptoms of PE, PA or CTPA that } \\
\text { could be performed within } 48 \text { hours }\end{array}$ \\
\hline
\end{tabular}

Exclusion criteria: (1) age younger than 18 years or older than 80 years, (2) advanced psychiatric disease, (3) severe malnutrition or expected survival time less than 6 months, (4) signs of massive unstable PE or 2 or more PEs or DVTs, (5) ongoing anticoagulant therapy, (6) thrombocytes $<70 \times 10^{9} \mathrm{~L}^{-1}$ or prolonged activated thromboplasmin time $>40$ seconds, (7) known HIV or hepatitis $C$ infection, (8) pregnancy, (9) acute myocardial infarction, (10) serum creatinine $>150 \mu \mathrm{mol} \mathrm{L-1}$, (11) ongoing treatment with metformin, (12) contraindication to the use of contrast media

Patients with high clinical suspicion of PE were recruited from the emergency departments of 2 hospitals in Stockholm, Sweden

\section{Index tests}

Rapid latex agglutination procedure (Tinaquant ${ }^{\oplus}$, Roche), quantitative test, cutoff level $<0.5 \mathrm{mg} / \mathrm{L}$ stated but not justified. D-dimer test was performed on a whole plasma sample

Target condition and ref- Acute PE was confirmed with computerised tomography pulmonary angiography (CTPA) or pulmonary erence standard(s) angiography (PA), or both, as the reference standard

Flow and timing

The reference standard tests were conducted within 48 hours of D-dimer testing

\section{Comparative}

Notes 
Soderberg 2009 (Continued)

Methodological quality

\begin{tabular}{llll}
\hline Item & Authors' judgement & Risk of bias & Applicability concerns \\
\hline
\end{tabular}

DOMAIN 1: Patient Selection

Was a consecutive or ran- Yes

dom sample of patients

enrolled?

\begin{tabular}{l} 
Was a case-control de- Yes \\
sign avoided? \\
\hline $\begin{array}{l}\text { Did the study avoid inap- Unclear } \\
\text { propriate exclusions? }\end{array}$
\end{tabular}

\begin{tabular}{lll}
\hline & Unclear & Unclear \\
\hline
\end{tabular}

DOMAIN 2: Index Test All tests

If a threshold was used, Yes

was it pre-specified?

Low Low

\section{DOMAIN 3: Reference Standard}

Is the reference stan- Yes

dards likely to correctly

classify the target condi-

tion?

\begin{tabular}{l}
\hline Low \\
\hline DOMAIN 4: Flow and Timing \\
\hline $\begin{array}{l}\text { Was there an appropriate Yes } \\
\text { interval between index } \\
\text { test and reference stan- } \\
\text { dard? }\end{array}$ \\
$\begin{array}{l}\text { Were all patients includ- Yes } \\
\text { ed in the analysis? }\end{array}$ \\
\hline
\end{tabular}

\section{Sohne 2004}

\section{Study characteristics}

\begin{tabular}{ll}
\hline Patient sampling & Prospective cross-sectional study \\
\hline $\begin{array}{l}\text { Patient characteristics and } \\
\text { setting }\end{array}$ & $\begin{array}{l}538 \text { patients ( } 72 \% \text { of } 747) ; 72 \% \text { of study participants (people at low risk of PE) were outpatients. } \\
\text { Mean age of people with PE was } 62 \text { years (range } 14 \text { to } 95 \text { ), those without PE had a mean age of } 52 \\
\text { years (17 to 92) }\end{array}$
\end{tabular}


Sohne 2004 (Continued)

Inclusion criteria: a consecutive sample of patients recruited from the Amsterdam Medical Centre (AMC) with clinical suspicion of PE, but non-high clinical probability

Exclusion criteria: younger than 18 years of age, pregnant, had received vitamin $\mathrm{K}$ antagonists or heparin at a therapeutic dose for longer than 24 hours, had already undergone objective testing for venous thromboembolism, had an indication for thromboembolism, written informed consent could not be obtained

CPR used to calculate a pre-test probability was Wells, and a score $\leq 4$ was regarded as a non-high probability of PE

Index tests

Plasma D-dimer concentration was measured by a quantitative rapid immunoturbidimetric Ddimer assay (Tinaquant D-dimer ${ }^{\oplus}$, Roche Diagnositica, Mannheim, Germany). The cutoff value for a positive test result was $0.5 \mathrm{mg} / \mathrm{L}$, which was stated but was not justified

Target condition and reference standard(s)
The reference standard was V/Q scanning in combination with compression ultrasound or pulmonary angiography

Flow and timing Timing between index and reference standard tests was not reported

\section{Comparative}

Notes Study authors reported 3-month follow-up of all patients to document the accuracy and safety of
the use of D-dimer in a low probability group

\section{Methodological quality}

\begin{tabular}{llll}
\hline Item & Authors' judgement & Risk of bias & Applicability concerns \\
\hline
\end{tabular}

\section{DOMAIN 1: Patient Selection}

Was a consecutive or random Yes

sample of patients enrolled?

Was a case-control design Yes
avoided?

Did the study avoid inappro- Yes priate exclusions?

\begin{tabular}{lll}
\hline & Low & Low \\
\hline DOMAIN 2: Index Test All tests & &
\end{tabular}

If a threshold was used, was it Yes

pre-specified?

\begin{tabular}{llll}
\hline LOMAIN 3: Reference Standard & Low & \\
\hline Is the reference standards like- Yes & & Unclear \\
ly to correctly classify the tar- \\
get condition?
\end{tabular}

\section{DOMAIN 4: Flow and Timing}


Sohne 2004 (Continued)

Was there an appropriate interval between index test and reference standard?

Were all patients included in the analysis?

CTPA: computerised tomography pulmonary angiography

CPR: clinical prediction rule

$\mathrm{CT}$ : computerised tomography

CTA: computerised tomography angiography

DVT: deep vein thrombosis

HIV: human immunodeficiency virus

IV: intravenous

MDCT: Multiple detector computerised tomography

NVP: negative predictive values

PA: pulmonary angiography

PE: pulmonary embolism

$\mathrm{V} / \mathrm{Q}$ : ventilation/perfusion

VTE: venous thromboembolism

Characteristics of excluded studies [ordered by study ID]

\begin{tabular}{|c|c|}
\hline Study & Reason for exclusion \\
\hline Barsotti 1987 & No $2 \times 2$ data; only $6 / 20$ patients had pulmonary embolism \\
\hline Bounameaux 1988 & No CPR was used to assess patient pre-test probability \\
\hline Bounameaux 1991 & No CPR that met eligibility criteria was used to assess patient pre-test probability \\
\hline Bounameaux 1992 & Deep venous thrombosis, not PE \\
\hline Christopher Study & Not a diagnostic test accuracy study - a therapeutic impact study \\
\hline Courtney 2008 & Patients with -ve D-dimer results did not receive reference standard imaging tests \\
\hline de Moerloose 1996 & No CPR was used to assess pre-test probability \\
\hline deBastos 2008 & Patients with -ve D-dimer results did not receive reference standard imaging tests \\
\hline Demers 1992 & No CPR was used to assess pre-test probability \\
\hline Djurabi 2009 & Patients with -ve D-dimer results did not receive reference standard imaging tests \\
\hline Douma 2011 & $\begin{array}{l}\text { Not all members of population were treated in an outpatient setting, and data were not presented } \\
\text { separately }\end{array}$ \\
\hline Eilas 2005 & No $2 \times 2$ data, reference standard unclear \\
\hline Faivre 1990 & No CPR was used to assess pre-test probability \\
\hline Friera-Reyes 2005 & Data on patients with +ve D-dimer were not included in the results \\
\hline
\end{tabular}




\begin{tabular}{|c|c|}
\hline Study & Reason for exclusion \\
\hline Gavaud 1996 & No CPR was used to assess pre-test probability \\
\hline Geersing 2012 & $\begin{array}{l}\text { Not all members of population were treated in an outpatient setting; data for those treated in an } \\
\text { outpatient setting were not presented separately }\end{array}$ \\
\hline Ghanima 2005 & Patients with -ve D-dimer results did not receive reference standard imaging tests \\
\hline Ghanima 2007 & Patients with -ve D-dimer results did not receive reference standard imaging tests \\
\hline Goekoop 2007 & Patients with -ve D-dimer results did not receive reference standard imaging tests \\
\hline Harper 2007 & $\begin{array}{l}\text { Not all members of population were treated in an outpatient setting; CPR (e.g. Wells) not used, no } \\
\text { reference standards }\end{array}$ \\
\hline Hirai 2007 & $\begin{array}{l}\text { DTA data for D-dimer not available - presented only for pulmonary angiography computerised to- } \\
\text { mography (PACT) }\end{array}$ \\
\hline Hochuli 2007 & No $2 \times 2$ data \\
\hline Hogg 2005 & $\begin{array}{l}\text { Reference standard tests included other D-dimer tests (IL D-dimer }{ }^{\mathrm{TM}} \text { (Instrumentation Laboratory, } \\
\text { Aragon, Barcelona, Spain) and MDA D-dimerTM (Organon Teknika BV Boseind, Boxtel, The Nether- } \\
\text { lands)) }\end{array}$ \\
\hline Kabrhel 2007 & $\begin{array}{l}\text { Reference standard PET/CT, incomplete verification: only 183/541 (34\%) patients received a refer- } \\
\text { ence standard test }\end{array}$ \\
\hline Kline 1997 & No CPR was used to assess pre-test probability \\
\hline Kline 2002 & Not a diagnostic test accuracy study - a prognostic study \\
\hline Kline 2006 & Incomplete verification; not all patients received a reference standard \\
\hline Kovacs 2001 & Patients with -ve D-dimer results did not receive reference standard imaging tests \\
\hline Laaban 1997 & No CPR was used to assess pre-test probability \\
\hline LeGal 2006 & CPR used does not meet review eligibility criteria \\
\hline Legani 2009 & Incomplete verification; not all patients received a reference standard \\
\hline Lucassen 2010 & $\begin{array}{l}\text { Primary care outpatient population from Christopher study; not a diagnostic test accuracy study - a } \\
\text { therapeutic impact study }\end{array}$ \\
\hline Lucassen 2013 & $\begin{array}{l}\text { This study is a summary and interpretation based on data published by the AMUSE study - Geersing } \\
2012\end{array}$ \\
\hline Parent 2007 & $\begin{array}{l}\text { Not all members of population were treated in an outpatient setting; data for those treated in an } \\
\text { outpatient setting were not presented separately }\end{array}$ \\
\hline Park 2008 & $\begin{array}{l}\text { Population included hospital inpatients. Contacted study authors for separate outpatient data - no } \\
\text { response }\end{array}$ \\
\hline Perrier 1996 & No CPR was used to assess pre-test probability \\
\hline Perrier 1997 & CPR does not meet review eligibility criteria \\
\hline
\end{tabular}




\begin{tabular}{|c|c|}
\hline Study & Reason for exclusion \\
\hline Ray 2006 & No CPR was used to assess pre-test probability \\
\hline Reber 2007 & Management study; lab-based study by the pharmaceutical industry - no reference standards \\
\hline Righini 2004 & Patients with -ve D-dimer results did not receive reference standard imaging tests \\
\hline Scarvelis 2008 & Patients with -ve D-dimer results did not receive reference standard imaging tests \\
\hline Sebestyen 1990 & Index test not a D-dimer (Fibrinopeptide A - FpA); no CPR \\
\hline Soo Hoo 2011 & Incomplete reference standard \\
\hline Soons 2000 & No CPR was used to assess pre-test probability \\
\hline Than 2009 & $\begin{array}{l}\text { No pre-test probability performed - some post-test probability performed, but numbers of patients } \\
\text { who received it not reported }\end{array}$ \\
\hline Waser 2005 & Deep venous thrombosis, not PE \\
\hline Yamaki 2007 & Deep venous thrombosis, not PE \\
\hline
\end{tabular}

CPR: clinical prediction rule

CT: computed tomography

DTA: diagnostic test accuracy

PE: pulmonary embolism

PET: positron emission tomography

-ve: negative

+ve: positive

Characteristics of studies awaiting classification [ordered by study ID]

\section{Ahamad 2000}

\section{Study characteristics}

Patient sampling

Patient characteristics and setting

Index tests

Target condition and reference standard(s)

Flow and timing

Comparative

Notes Unable to obtain report

\section{Study characteristics}




\section{Undurrage 2001 (Continued)}

Patient sampling

Patient characteristics and setting

Index tests

Target condition and reference standard(s)

Flow and timing

Comparative

Notes

Unable to obtain report

\section{ADDITIONAL TABLES}

Table 1. Examples of CPRs used for a pre-test probability score for PE

CPR Predictive elements and scoring system

Three-level Wells score

Predictive elements of this CPR include clinical signs and symptoms of DVT ( 3 points), alternative diagnosis less likely than PE ( 3 points), heart rate $>100$ beats per minute ( 1.5 points), immobilisation for longer than 3 days or recent ( $<4$ weeks) surgery (1.5 points), previous VTE ( 1.5 points), haemoptysis (1 point), cancer treatment in the previous 6 months or palliative care (1 point)

Low probability - less than 2; intermediate probability - 2 to 6 ; high probability - more than 6

Two-level Wells score

Predictive elements for the 2-level Wells score are the same as for the 3-level Wells score, but patients are categorised into 2 as opposed to 3 categories, PE likely or PE unlikely based on a score of more than 4 or 4 or fewer points, respectively
Same predictive elements are used as for the 3-level Wells score, but the point scoring has been simplified - each item now scores 1 point. Patients are regarded as low risk if they have 1 point or less, and as high risk if they score more than 1
Geneva score

Predictive elements of the Geneva score include recent surgery (3 points), previous history of PE or DVT ( 2 points), heart rate $>100$ beats per minute ( 1 point), 60 to 79 years old ( 1 point), 80 years old or older (2 points), chest radiograph showing atelectasis (1 point), chest radiograph showing elevated hemidiaphragm (1 point), partial pressure of oxygen $\left(\mathrm{PaO}_{2}\right)<49 \mathrm{~mm} \mathrm{Hg}$ (4 points), $\mathrm{PaO}_{2} 49$ to $59 \mathrm{~mm} \mathrm{Hg}$ (3 points), $\mathrm{PaO}_{2} 60$ to $71 \mathrm{~mm} \mathrm{Hg}$ (2 points), $\mathrm{PaO}_{2} 72$ to $82 \mathrm{~mm} \mathrm{Hg}$ (1 point) and partial pressure of carbon dioxide $\left(\mathrm{PaCO}_{2}\right)<36 \mathrm{~mm} \mathrm{Hg}$ (2 points), $\mathrm{PaCO}_{2} 36$ to $38.9 \mathrm{~mm} \mathrm{Hg}$ (1 point)

Risk of PE is scored low (0 to 4 points), intermediate ( 5 to 8 points) or high ( 9 or more points)
Predictive elements of the revised Geneva score include age $>65$ years (1 point), previous history of PE or DVT (3 points), surgery with general anaesthesia or fracture within 1 month of symptoms arising ( 2 points), active malignancy ( 2 points), heart rate 75 to 94 beats per minute ( 3 points), heart rate $>94$ beats per minute ( 5 points), pain on leg venous palpation and unilateral oedema ( 4 points), haemoptysis ( 2 points) and unilateral leg pain ( 3 points)

This CPR is scored low risk ( 0 to 3 points), intermediate risk (4 to 10 points) or high risk (11 or more points)
Same predictive elements are used as for the revised Geneva score, but point scoring has been simplified. Each item now scores 1 point 
Table 1. Examples of CPRs used for a pre-test probability score for PE (Continued) Risk of PE is scored low ( 0 to 1 point), intermediate ( 2 to 4 points) or high ( 5 or more points)

\section{Charlotte rule}

Elements of the Charlotte rule include $>50$ years old, heart rate higher than systolic blood pressure, unexplained hypoxaemia $\left(\mathrm{O}_{2}<95 \%\right)$, recent surgery (previous 4 weeks), haemoptysis and unilateral leg swelling

Risk score from the Charlotte rule is classified as safe (all predictive elements absent) or unsafe (any of the predictive elements present)

CPR: clinical prediction rule

DVT: deep vein thrombosis

PE: pulmonary embolism

VTE: Venous thromboembolism

\section{APPENDICES}

\section{Appendix 1. MEDLINE search strategy}

Database: Ovid MEDLINE $(R)<1946$ to November Week 3 2013>

Search Strategy:

1 exp Pulmonary Embolism/ (31347)

2 (pulmonary adj embol\$).ti,ab. (25289)

3 (pulmonary adj thrombo\$).ti,ab. (3289)

4 (lung adj embol\$).ti,ab. (377)

5 (lung adj thrombo\$).ti,ab. (59)

6 (PE or PTE).ti,ab. (23195)

7 or/1-6 (59563)

8 Fibrin Fibrinogen Degradation Products/an, me [Analysis, Metabolism] (5667)

9 Biological Markers/an, bl, me [Analysis, Blood, Metabolism] (120309)

10 Enzyme-Linked Immunosorbent Assay/ (130387)

11 "Nephelometry and Turbidimetry"/ (6377)

12 d-dimer.ti,ab. (5726)

13 (fibrin adj2 d).ti,ab. (532)

14 dimeri?ed plasmin.ti,ab. (6)

15 elisa?.ti,ab. (112004)

16 elfa?.ti,ab. (120)

17 enzyme linked.ti,ab. (70920)

18 latex agglutination.ti,ab. (3168)

19 (latex adj3 assay?).ti,ab. (621)

20 blood agglutination.ti,ab. (40) 
21 Immunoturbidimetr\$.ti,ab. (874)

22 turbidimetr\$.ti,ab. (2576)

23 SimpliRed.ti,ab. (76)

24 Minutex.ti,ab. (6)

25 NycoCard.ti,ab. (45)

26 "Instant I.A".ti,ab. (7)

27 Vidas.ti,ab. (501)

28 LIATEST.ti,ab. (47)

29 ("IL test" or IL-DD).ti,ab. (29)

30 Turbiquant.ti,ab. (5)

31 Asserachrom.ti,ab. (52)

32 Enzygnost.ti,ab. (200)

33 Fibrinostika.ti,ab. (6)

34 "BC DD".ti,ab. (1)

35 (Tinaquant or Tina-quant).ti,ab. (94)

36 TriniLIZE.ti,ab. (0)

37 biopool.ti,ab. (31)

38 TintElize.ti,ab. (5)

39 HemosIL.ti,ab. (42)

40 Innovance-DD.ti,ab. (1)

41 stratus.ti,ab. (812)

42 FDP.ti,ab. (2331)

43 Dimertest.ti,ab. (25)

44 (LPIA or EIA).ti,ab. (8470)

45 or/8-44 (343616)

467 and 45 (2690)

\section{Appendix 2. EMBASE search strategy}

Database: Embase <1980 to 2013 Week 49>

Search Strategy:

1 lung embolism/ (58459)

2 (pulmonary adj embol\$).ti,ab. (34552)

3 (pulmonary adj thrombo\$).ti,ab. (4366)

4 (lung adj embol\$).ti,ab. (598)

5 (lung adj thrombo\$).ti,ab. (76) 
6 (PE or PTE).ti,ab. (33967)

7 or/1-6 (92164)

8 fibrin degradation product/cr [Drug Concentration] (1)

9 biological marker/cr [Drug Concentration] (14)

$10 \mathrm{D}$ dimer/cr [Drug Concentration] (13)

11 enzyme linked immunosorbent assay/ (205450)

12 turbidimetry/ (2792)

13 d-dimer.ti,ab. (8597)

14 (fibrin adj2 d).ti,ab. (652)

15 dimeri?ed plasmin.ti,ab. (5)

16 elisa?.ti,ab. (155486)

17 elfa?.ti,ab. (186)

18 enzyme linked.ti,ab. (78011)

19 Immunoturbidimetr\$.ti,ab. (1361)

20 turbidimetr\$.ti,ab. (3317)

21 latex agglutination.ti,ab. (3477)

22 (latex adj3 assay?).ti,ab. (735)

23 blood agglutination.ti,ab. (41)

24 SimpliRed.ti,ab. (89)

25 Minutex.ti,ab. (7)

26 NycoCard.ti,ab. (72)

27 "Instant I.A".ti,ab. (8)

28 Vidas.ti,ab. (729)

29 LIATEST.ti,ab. (114)

30 ("IL test" or IL-DD).ti,ab. (88)

31 Turbiquant.ti,ab. (8)

32 Asserachrom.ti,ab. (130)

33 Enzygnost.ti,ab. (252)

34 Fibrinostika.ti,ab. (7)

35 "BC DD".ti,ab. (1)

36 (Tinaquant or Tina-quant).ti,ab. (167)

37 TriniLIZE.ti,ab. (2)

38 biopool.ti,ab. (49)

39 TintElize.ti,ab. (9)

40 (HemosIL-DD or HemosIL-DDHS).ti,ab. (5)

D-dimer test for excluding the diagnosis of pulmonary embolism (Review) 
41 Innovance-DD.ti,ab. (2)

42 stratus.ti,ab. (1030)

43 FDP.ti,ab. (2583)

44 Dimertest.ti,ab. (27)

45 (LPIA or EIA).ti,ab. (10588)

46 or/8-45 (284160)

477 and 46 (3250)

Appendix 3. CINAHL search strategy

Interface

- EBSCOhost Research Databases

Search Screen

- Advanced Search

Database

- CINAHL Plus

19 December 2013

\begin{tabular}{|c|c|c|}
\hline S47 & S7 AND S46 & 711 \\
\hline S46 & 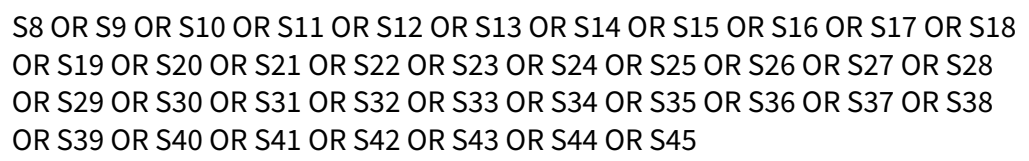 & 37,766 \\
\hline S45 & TX LPIA or EIA & 381 \\
\hline S44 & TX Dimertest & 2 \\
\hline S43 & TX FDP & 103 \\
\hline S42 & TX stratus & 50 \\
\hline S41 & TX Innovance-DD & 0 \\
\hline S40 & TX HemosIL & 6 \\
\hline S39 & TX TintElize & 0 \\
\hline S38 & TX biopool & 4 \\
\hline S37 & TX TriniLIZE & 0 \\
\hline S36 & TX Tinaquant or Tina-quant & 14 \\
\hline S35 & TX BC DD & 2 \\
\hline
\end{tabular}

D-dimer test for excluding the diagnosis of pulmonary embolism (Review)

Copyright $\odot 2016$ The Cochrane Collaboration. Published by John Wiley \& Sons, Ltd. 
(Continued)

\begin{tabular}{|c|c|c|}
\hline S34 & TX Fibrinostika & 0 \\
\hline S33 & TX Enzygnost & 6 \\
\hline S32 & TX Asserachrom & 1 \\
\hline S31 & TX Turbiquant & 0 \\
\hline S30 & TX IL test or IL-DD & 82 \\
\hline S29 & TX LIATEST & 5 \\
\hline S28 & TX Vidas & 25 \\
\hline S27 & TX Instant I.A & 0 \\
\hline S26 & TX NycoCard & 8 \\
\hline S25 & TX Minutex & 0 \\
\hline S24 & TX SimpliRed & 18 \\
\hline S23 & TX turbidimetr* & 270 \\
\hline S22 & TX Immunoturbidimetr* & 71 \\
\hline S21 & TX blood agglutination & 239 \\
\hline S20 & TX latex N3 assay? & 6 \\
\hline S19 & TX latex agglutination & 107 \\
\hline S18 & TX enzyme linked & 12,863 \\
\hline S17 & TX elfa? & 10 \\
\hline S16 & TX elisa? & 249 \\
\hline S15 & TX dimeri?ed plasmin & 1 \\
\hline S14 & TX fibrin N2 d & 60 \\
\hline S13 & TX d-dimer & 808 \\
\hline S12 & (MH "Nephelometry and Turbidimetry") & 215 \\
\hline S11 & (MH "Nephelometry and Turbidimetry") & 215 \\
\hline S10 & (MH "Enzyme-Linked Immunosorbent Assay") & 10,786 \\
\hline S9 & (MH "Fibrin Fibrinogen Degradation Products/AN/BL/ME") & 540 \\
\hline S8 & (MH "Biological Markers+/AN/BL/ME") & 24,146 \\
\hline S7 & S1 OR S2 OR S3 OR S4 OR S5 OR S6 & 15,735 \\
\hline
\end{tabular}


(Continued)

\begin{tabular}{lll} 
S6 & TX PE or PTE & 9,671 \\
\hline S5 & TX lung N3 thrombo* & 38 \\
\hline S4 & TX lung N3 embol* & 66 \\
\hline S3 & TX pulmonary N3 thrombo* & 1,347 \\
\hline S2 & TX pulmonary N3 embol & 6,589 \\
\hline S1 & (MH "Pulmonary Embolism")
\end{tabular}

Appendix 4. LILACS search strategy

\begin{tabular}{ll}
\hline Database : & LILACS 12 December 2013 \\
\hline Search on : & (Fibrin Fibrinogen Degradation Products or Biological Markers or Enzyme-Linked Immunosor- \\
& bent Assay) [Subject descriptor] or (d-dimer or fibrin or (dimerised and plasmin) or elisa or \\
& elfa or (enzyme and linked) or (latex and agglutination) or (latex and assay) or (blood and \\
& agglutination) or Immunoturbidimetr\$ or turbidimetr\$ or SimpliRed or Minutex or Nyco- \\
& Card or (Instant and I.A) or Vidas or LIATEST or (IL and test) or IL-DD or Turbiquant or Asser- \\
& achrom or Enzygnost or Fibrinostika or (BC and DD) or Tinaquant or Tina-quant) [Words] and \\
& (Pulmonary Embolism [Subject descriptor]) or ((pulmonary and embol\$) or (pulmonary and \\
& thrombo $\$$ ) or (lung and embol\$) or (lung and thrombo $\$$ ) or PE or PTE) [Words]
\end{tabular}

References found: $\quad \mathbf{6 2}$ [refine]

Appendix 5. DARE (Database of Abstracts of Reviews of Effects) and Health Technology Assessment Database (HTA) search strategy

\begin{tabular}{|c|c|c|}
\hline & Issue 112013 & \\
\hline$\# 1$ & MeSH descriptor: [Pulmonary Embolism] explode all trees & 874 \\
\hline$\# 2$ & pulmonary near/3 embol*:ti,ab,kw (Word variations have been searched) & 1679 \\
\hline \#3 & pulmonary near/3 thromb*:ti,ab,kw (Word variations have been searched) & 515 \\
\hline \#4 & lung near/3 embol*:ti,ab,kw (Word variations have been searched) & 165 \\
\hline \#5 & lung near/3 thromb* & 64 \\
\hline \#6 & PE or PTE:ti,ab,kw (Word variations have been searched) & 1320 \\
\hline$\# 7$ & $\# 1$ or \#2 or \#3 or \#4 or \#5 or \#6 & 2928 \\
\hline \#8 & $\begin{array}{l}\text { MeSH descriptor: [Fibrin Fibrinogen Degradation Products] explode all trees } \\
\text { and with qualifier(s): [Analysis - AN, Metabolism - ME] }\end{array}$ & 389 \\
\hline
\end{tabular}


(Continued)

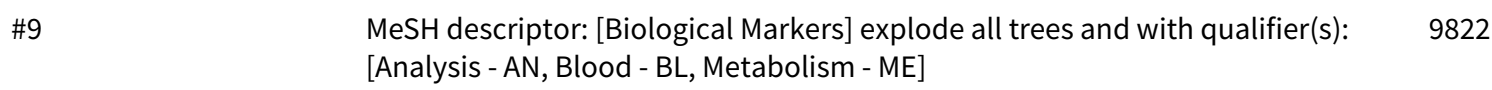

\begin{tabular}{lll}
\hline$\# 10$ & MeSH descriptor: [Enzyme-Linked Immunosorbent Assay] explode all trees & 1977 \\
\hline$\# 11$ & MeSH descriptor: [Nephelometry and Turbidimetry] explode all trees & 64 \\
\hline$\# 12$ & $\begin{array}{l}\text { d-dimer or (fibrin near/2 d) or (dimeri* near/2 plasmin) or elisa or elfa or "en- } \\
\text { zyme linked" or "latex agglutination" or (latex near/j3 assay) or "blood aggluti- } \\
\text { nation" or Immunoturbidimetr* or turbidimetr or SimpliRed or Minutex or Ny- } \\
\text { coCard or "Instant I.A" or Vidas or LIATEST or "IL test" or "IL-DD" or Turbiquant } \\
\text { or Asserachrom or Enzygnost or Fibrinostika or "BC DD" or Tinaquant or "Tina- } \\
\text { quant" or TriniLIZE or biopool or TintElize or HemosIL or "Innovance-DD" or } \\
\text { stratus or FDP or Dimertest or LPIA or EIA:ti,ab,kw (Word variations have been } \\
\text { searched) }\end{array}$ \\
\hline$\# 13$ & $\# 8$ or \#9 or \#10 or \#11 or \#12 & 14492 \\
\hline$\# 14$ & $\# 7$ and \#13 & 110 \\
\hline
\end{tabular}

All Results (110)

Cochrane Reviews (1)

AllReviewProtocol

Other Reviews (17) Trials (84) Methods Studies (0) Technology Assessments (1)

Economic Evaluations (7) Cochrane Groups (0)

\section{Appendix 6. ISI Conference Proceedings Citation Index - Science search strategy}

\section{December 2013}

Topic=(d-dimer) AND Topic=(pulmonary embolism or Thromboembolism or VTE)

Timespan=All years. Databases=CPCI-S, CCR-EXPANDED, IC

216

\section{Appendix 7. British Library Zetoc search strategy}

\section{December 2013}

16 for: conference: $d$-dimer and embolism

69 for: conference: $d$-dimer and thrombo*

\section{Appendix 8. MEDION search strategy}

19 December 2013

d-dimer: 9 results

\section{Appendix 9. World Health Organization International Clinical Trials Registry search strategy} 18 December 2013

21 records for 19 trials found for: $\mathrm{d}$-dimer and embolism 


\section{Appendix 10. ClinicalTrials.gov search strategy}

\section{December 2013}

65 studies found for: $d$-dimer and embolism

\section{Appendix 11. Current Controlled Trials search strategy}

18 December 2013

4 studies found for: $d$-dimer and embolism

Appendix 12. QUADAS-2

\section{Domains, signalling questions Rating criteria \\ (SQ) and applicability}

\section{Domain 1: Patient selection}

A. Risk of bias Describe the methods of patients' selection given in the paper:

SQ1: Was a consecutive or random sample of patients enrolled?

Yes: It is stated that the sample was consecutive or a random sample

No: It is stated that the sample was not consecutive or a random sample

Unclear: The method of sampling is ambiguous

Yes: The study excluded patients without CPR scores

SQ2: Did the study avoid inappropriate exclusions?

No: The study excluded patients who had received a PTP score using CPRs

Unclear: The test history of the patients in the study is not revealed in the report

SQ3: Did the study avoid inappropriate inclusions?

Yes: The study included only outpatients who had received a PTP score for PE using a CPR

No: The study included some inappropriate patients, for example, those without a PTP score from a CPR, or included inpatients

Unclear: The study's inclusion criteria allow for inappropriate inclusions

Applicability Question 1: Are there concerns that the included patients and setting do not match the review question?
High: The study population meets the eligibility criteria

Low: The patient population is skewed in some way, for example the study includes mainly younger patients

Unclear: Not enough information is given about the study population

\footnotetext{
B. Concerns regarding applicability
}

Give the paper's description of the inclusion/exclusion criteria, including setting, prior tests, symptoms here

\section{Domain 2: Index test}

A. Risk of bias

SQ1: If a threshold was used was it prespecified?
Give the paper's description of the D-dimer assay, how it was conducted and interpreted including the training of the individual of those carrying out the test

Yes: Plasma D-dimer levels are prespecified in the study methods section as a positive test result

No: The threshold for a positive test result is not prespecified

Unclear: It is unclear if a threshold was used 
(Continued)

B. Concerns regarding applica-

bility

AQ2: Are there concerns that the index test, its conduct or its interpretation differ from the review question?
Yes: The plasma D-Dimer test did not use standard methods and is unvalidated

No: The presence of plasma D-dimer was detected using standard D-dimer test methods previously validated

Unclear: The basis of the outcome is unclear

\section{Domain 3: Reference standard}

A. Risk of bias

SQ1: Is the reference standard likely to correctly classify the target condition?
Give the paper's description of the pulmonary angiography, scintigraphy, computed tomography PA and follow-up and how they were conducted and interpreted including the training of the individual of those carrying out the test
Yes: The reference standard(s) was either pulmonary angiography, CTPA, MRPA, or V/Q scanning

No: The reference standard(s) was not any of the above

Unclear: Information regarding the conduct of the reference standard is insufficient
SQ2: Were the reference standard test results interpreted without knowledge of the index test results?
Yes: The person classifying the RS test results was unaware of the D-dimer test results

No: The person classifying the RS test results was aware of the D-dimer test results

Unclear: No information is available regarding the blinding of test results
SQ3: Did the person conducting the pulmonary angiography, $\mathrm{V} /$ Q scanning, CTPA, or MRPA have expertise comparable to a radiologist?

Yes: It is stated that a radiologist or similar (e.g. vascular specialist with an interest in VTE) read the test results

No: The person conducting the pulmonary angiography, V/Q scanning, CTPA, or MRPA was not a radiologist or similar

Unclear: The expertise and background discipline of the reader is not made clear

Applicability: Could the reference standard, its conduct, or its interpretation have introduced bias?
High: The RS tests were performed by a person with expertise and were interpreted blind

Low: The RS tests were not performed by a person with expertise or were not interpreted blind Unclear: No information about the persons conducting the tests, or interpreting the results is given

\section{Domain 4: Flow and timing}

\section{A. Risk of bias}

Describe the reasons why any patient recruited into the study did not contribute to the $2 \times 2$ table (i.e. patients who did not undergo the RS tests) referring to the flow diagram
SQ1: was there an appropriate interval between the index test and the reference standard?
Yes: The index and reference standard tests were all conducted within 7 days of each other

No: Some of the reference standard test results were obtained after more than 7 days

Unclear: No information about the relative timing of the tests is provided
SQ2: Did all the patients receive the same reference standard?
Yes: A complete set of RS test results are available for all study patients

No: The RS results are not available for all patients, or some patients had follow-up only

Unclear: It is not clear whether all patients received an acceptable reference standard
SQ3: Were all patients included in the final analysis?
Yes: Data for all study patients are reported

D-dimer test for excluding the diagnosis of pulmonary embolism (Review) 


\begin{tabular}{lll}
\hline Date & Event & Description \\
\hline 23 September 2016 & Amended & $\begin{array}{l}\text { Correction of minor error and omission in plain language sum- } \\
\text { mary identified by German translation team }\end{array}$ \\
\hline
\end{tabular}

\section{CONTRIBUTIONS OFAUTHORS}

The whole review team has contributed to this review. KW developed the search strategy. FC and AA applied eligibility criteria, extracted data from studies, performed an assessment of study quality and entered data into Review Manager. FMC provided expert statistical and $\mathrm{KS}$ and DK expert clinical advice.

\section{DECLARATIONS OF INTEREST}

FC: none known.

AA: none known.

$\mathrm{KW}$ : none known.

KS: Dr Sheares is a member of the National Institute for Health and Care Excellence Venous Thromboembolic Diseases Guidelines Committee and of the British Thoracic Society Outpatient Management of Pulmonary Embolism Guidelines Committee. Dr Sheares has received support from Actelion, Bayer, GSK, Pfizer and United Therapeutics to attend educational meetings/conferences.

DK reports that he received consultancy fees for advisory board roles for Pfizer, Daiichi-Sankyo, Boehringer Ingelheim, Sobi, Baxalta and Octapharma; lecture fees from NovoNordisk, Boehringer Ingelheim, Bayer and Pfizer; and meeting expenses from Bayer and CSL to attend ISTH and EAHAD meetings.

FMC: none known.

This review forms part of work funded by a National Institute of Health Research (NIHR) Cochrane programme grant. The review was conducted independently of our funders, the NIHR. The NIHR had no input on the conduct or results of the review.

\section{SOURCES OF SUPPORT}

\section{Internal sources}

- No sources of support supplied

\section{External sources}

- National Institute for Health Research (NIHR), UK.

This project was supported by the NIHR, via Cochrane Programme Grant funding to Cochrane Vascular (10/4001/14). The views and opinions expressed therein are those of the review authors and do not necessarily reflect those of the Systematic Reviews Programme, NIHR, NHS or the Department of Health.

- Chief Scientist Office, Scottish Government Health Directorates, Scottish Government, UK.

The Cochrane Vascular editorial base is supported by the Chief Scientist Office.

\section{DIFFERENCES BETWEEN PROTOCOL AND REVIEW}

We have added accident and emergency (A\&E) room to the study setting to reflect conventional reporting that we encountered in studies considered for inclusion in this review. We were unable to carry out a search of the Cochrane DTA Register. 


\section{N D X T ERMS}

\section{Medical Subject Headings (MeSH)}

Acute Disease; Biomarkers [blood]; Cross-Sectional Studies; False Negative Reactions; False Positive Reactions; Fibrin Fibrinogen Degradation Products [*analysis]; Pulmonary Embolism [blood] [^diagnosis]; Reference Standards; Venous Thromboembolism [blood] [diagnosis]

\section{MeSH check words}

Adult; Humans 